Annales Geophysicae (2002) 20: 661-677 (c) European Geophysical Society 2002

\title{
Seasonal variations of the semi-diurnal and diurnal tides in the MLT: multi-year MF radar observations from $2-70^{\circ} \mathrm{N}$, modelled tides (GSWM, CMAM)
}

\author{
A. H. Manson ${ }^{1}$, C. Meek ${ }^{1}$, M. Hagan $^{2}$, J. Koshyk ${ }^{3}$, S. Franke ${ }^{4}$, D. Fritts ${ }^{5}$, C. Hall ${ }^{6}$, W. Hocking ${ }^{7}$, K. Igarashi ${ }^{8}$, \\ J. MacDougall ${ }^{7}$, D. Riggin ${ }^{5}$, and R. Vincent ${ }^{9}$ \\ ${ }^{1}$ Institute of Space and Atmospheric Studies, University of Saskatchewan, Canada \\ ${ }^{2}$ NCAR, Boulder NCAR, Boulder, USA \\ ${ }^{3}$ Department of Physics, University of Toronto, Canada \\ ${ }^{4}$ Space Science and Remote Sensing Laboratory, University of Illinois, USA \\ ${ }^{5}$ Colorado Research Associates (a Division of Northwest Research Associates), Boulder, USA \\ ${ }^{6}$ Auroral Observatory, University of Troms $\emptyset$, Norway \\ ${ }^{7}$ Department of Physics and Astronomy, University of Western Ontario, Canada \\ ${ }^{8}$ Communications Research Laboratory, Tokyo, Japan \\ ${ }^{9}$ Department of Physics and Mathematical Physics, University of Adelaide, Australia
}

Received: 20 July 2001 - Revised: 14 December 2001 - Accepted: 18 December 2001

\begin{abstract}
In an earlier paper (Manson et al., 1999a) tidal data (1990-1997) from six Medium Frequency Radars (MFR) were compared with the Global Scale Wave Model (GSWM, original 1995 version). The radars are located between the equator and high northern latitudes: Christmas Island $\left(2^{\circ} \mathrm{N}\right)$, Hawaii $\left(22^{\circ} \mathrm{N}\right)$, Urbana $\left(40^{\circ} \mathrm{N}\right)$, London $\left(43^{\circ} \mathrm{N}\right)$, Saskatoon $\left(52^{\circ} \mathrm{N}\right)$ and Troms $\varnothing\left(70^{\circ} \mathrm{N}\right)$. Common harmonic analysis was applied, to ensure consistency of amplitudes and phases in the $75-95 \mathrm{~km}$ height range. For the diurnal tide, seasonal agreements between observations and model were excellent while for the semi-diurnal tide the seasonal transitions between clear solstitial states were less well captured by the model.

Here the data set is increased by the addition of two locations in the Pacific-North American sector: Yamagawa $31^{\circ} \mathrm{N}$, and Wakkanai $45^{\circ} \mathrm{N}$. The GSWM model has undergone two additional developments $(1998,2000)$ to include an improved gravity wave (GW) stress parameterization, background winds from UARS systems and monthly tidal forcing for better characterization of seasonal change. The other model, the Canadian Middle Atmosphere Model (CMAM) which is a General Circulation Model, provides internally generated forcing (due to ozone and water vapour) for the tides.

The two GSWM versions show distinct differences, with the 2000 version being either closer to, or further away from, the observations than the original 1995 version. CMAM provides results dependent upon the GW parameterization
\end{abstract}

Correspondence to: A. H. Manson

(manson@dansas.usask.ca) scheme inserted, but one of the schemes provides very useful tides, especially for the semi-diurnal component.

Key words. Meteorology and atmospheric dynamics (middle atmosphere dynamics; waves and tides)

\section{Introduction}

The study of atmospheric tides in the middle atmosphere (MA) is important for a variety of reasons. Their amplitudes are generally the largest of all the atmospheric oscillations (Gravity, Planetary, Tidal waves), e.g. Manson and Meek (1986), and although seasonal variations are usually quite strong at all latitudes they are still the most regular and persistent oscillations. Tides are known to have a significant impact upon the momentum balance in the lower thermosphere ( $>\sim 90 \mathrm{~km}$ ), especially at lower latitudes (Forbes et al., 1993; Miyahara et al., 1993), and upon the distribution of atmospheric constituents (Shepherd et al., 1998; Ward, 1998). They also modulate the fluxes of propagating GW (Manson et al., 1998).

Tidal structures in the MA are extremely complex, so that successful modelling requires the understanding of a wide range of atmospheric phenomena, including radiational, chemical and dynamical. These include the distribution of ozone and water vapour in height, season and planetary location; the background winds and mean temperatures; molecular and eddy diffusivity; and gravity wave stress and Newtonian cooling effects. In mechanistic models like GSWM such processes are parameterized in the model. 
Hence newer or different versions of GSWM are not necessarily better or more realistic than earlier ones but may simply reflect the strong effect of a particular change in input data or in a parameterized process. Below, we briefly describe the year 2000 version of GSWM (GSWM 2000). All figures will contain data from that and the earliest version of the GSWM, as well as data from the MFR network (mainly Pacific-North American). The comparisons between the original 1995 version of GSWM (called as usual GSWM) and GSWM 2000 will be particularly interesting (Sects. 4 and 5) and they will illustrate the sensitivity to the changing characterizations, and also the advantages of monthly resolution. Our earlier paper (hereafter Paper 1, Manson et al., 1999a) compared GSWM with a seven year (1990-1997) MFR data set; here that set is supplemented with observations (1996) from Wakkanai $\left(45^{\circ} \mathrm{N}\right)$ and Yamagawa $\left(31^{\circ} \mathrm{N}\right)$.

The assessment of tides within a Global Circulation Model (GCM), in this case CMAM, is also challenging to the modelling enterprise. Here one is testing in a very comprehensive manner the internal consistency and comprehensive nature of the model. Elsewhere (Manson et al., 2001) we have analysed the seasonal outputs from CMAM for three GW parameterization experiments to obtain GW intensities, tidal amplitudes, and phases for the solar semi-diurnal and diurnal tides for 7 MFR locations. These were compared with the observed GW characteristics (Manson et al., 1999b) and tidal characteristics (in this case the tidal data were mainly from the 2 years of MFR observations in 1993/1994). Briefly, the modelled tides depended strongly upon parameterization, and the MFR comparisons led to a preference for the Medvedev and Klaassen (2000) scheme. Amplitudes from CMAM were quite similar to those observed for the semidiurnal tide; but modelled diurnal tides were much larger at low latitudes $\left(0-22^{\circ} \mathrm{N}\right)$, in the equinoxes, and at higher latitudes, in summer, than observed. The semi-diurnal tidal phases were often in very good agreement for CMAM and MFR with longer/shorter vertical wavelengths generally at lower/higher latitudes; while for the diurnal tide, although the phase gradients (height, latitude) were quite similar for the MFR and CMAM at lower latitudes, consistent with the short wavelength $S(1,1)$ mode, they differed significantly at higher latitudes. It will be interesting here to compare CMAM tides with not only a larger MFR data set (7 years rather than 2) but also with GSWM 2000 (Sect. 6).

\section{The models: GSWM, GSWM2000; CMAM}

GSWM is a two-dimensional linearized model that solves the Navier-Stokes equations for tidal and planetary wave perturbations as a function of latitude and altitude, for a specific wave periodicty and zonal wave number:

http://www.hao.ucar.edu/public/research/tiso/gswm/gswm.html.

Essential references for the GSWM include the following: Hagan et al., 1993, 1995; Manson et al., 1999a; Hagan et al., 1999. The last reference and the web-site describes the 1998 version of GSWM which is the foundation for GSWM2000.
GSWM2000 predicts monthly migrating diurnal and semidiurnal climatologies while both GSWM and GSWM1998 results are seasonal averages and only available for 4 months; January, April, July, and October. These are the middle months of the traditional seasons used here and elsewhere; for the northern hemisphere, winter (DJF); spring (MAM); summer (JJA); Autumn or Fall (SON). This monthly extension to the model capabilities is based on the assumption that it is reasonable to estimate monthly variations in tropospheric tidal forcing by interpolating between the 3-month average seasonal heating rates, parameterized by Groves (1982) and invoked in both GSWM and GSWM1998. Otherwise, the assumptions invoked in GSWM2000 are identical to those that characterized GSWM1998 (Hagan et al., 1999) with the single exception of the ozone model used to parameterize strato-mesopheric migrating tidal forcing. CIRA ozone climatologies (Keating et al., 1990) were used in both GSWM and GSWM2000, since Hagan et al. (1999) demonstrated negligible impact when UARS measurements replaced the CIRA model in GSWM1998. Preliminary evaluations of the GSWM2000 may be seen in Hagan et al. (2001) and Pancheva et al. (2001).

The following brief description gives the highlights of GSWM2000 in so far as it differs from the other model used, GSWM (originated in 1995). Both models use mean temperatures and densities from Hedin (1991), the same winds below $12 \mathrm{~km}$ (Groves, 1985, 1987) and tropospheric migrating tidal forcing (Groves, 1982). However while GSWM used middle atmosphere winds from Groves (1985, 1987) and an empirical wind-model due to Portnyagin and Solov'era (1992a, b), the latest GSWM versions (1998, 2000) use UARS-HRDI (High Resolution Doppler Interferometer) winds (Hagan et al., 1999; after Burrage et al., 1996). This is a significant change, as shown by Hagan et al. (1999). For ozone tidal forcing the CIRA distributions (Keating et al., 1990) are used for 1995 and 2000 versions. The models also use the same molecular and eddy diffusivity schemes and parameterizations for ion drag and Newtonian cooling effects. Gravity wave stress in the form of linear (Rayleigh) friction on the diurnal tide now varies monthly, with GSWM2000 equinox values an order of magnitude smaller than for the solstices (Hagan et al., 1999). The latter are very close to the constant values of stress used in GSWM. This change was initiated to provide diurnal tidal amplitudes at low latitudes which matched the large equinoctial analysed tides from the HRDI data (Burrage et al., 1995). The monthly diurnal and semi-diurnal data from GSWM2000 are obtained by using either input background data, which are inherently monthly, or by interpolation of the background data. Factors not included in either model include these: thermospheric in-site forcing and latent heat release due to convective activity in the troposphere. In all figures the GSWM data are shown for the middle month of the season only, as this month will be more representative of average conditions for the season and these were used in the model as background conditions.

The CMAM is a 3D spectral GCM extending from the ground to a height of approximately $100 \mathrm{~km}$ (Beagley et al., 
1997). The prognostic fields are expanded in a series of spherical harmonic functions with triangular truncation at total wavenumber $n=47$ (T47) corresponding to a horizontal grid spacing of about $400 \mathrm{~km}$. The model contains $50 \mathrm{lev}-$ els in the vertical with a resolution of approximately $3 \mathrm{~km}$ above the tropopause. Realistic surface topography, planetary boundary-layer effects, a full hydrological cycle, a parameterization of moist convective adjustment including the release of latent heat and comprehensive shortwave (solar) and long-wave (terrestrial) radiation schemes are all included in the model. The radiative effects of clouds are included also. Both diurnal and semi-diurnal global tides are forced by CMAM. The reader is referred to (Beagley et al., 1997) for further details.

The finite resolution of CMAM and other GCMs makes it impossible to represent explicitly the effects of $\mathrm{GW}$ with spatial scales smaller than the model grid spacing. (Note that resolved GW, with scales larger than the model grid spacing, are routinely excited in the model by a variety of sources including shear instabilities and flow over topography). In order to represent the effects of unresolved (subgridscale) GWs on the resolved flow, GW drag parameterization schemes are often invoked. The parameterization of drag due to the breaking of waves excited by subgrid-scale topography is described in McFarlane (1987) and this scheme is included in all simulations presented here. The effects of GW that may arise from unresolved non-orographic sources such as moist convection and dynamical shear instabilities in, for example, frontal zones, are represented in the data shown here by a scheme due to Medvedev and Klaassen (1995). A simple Rayleigh-drag "sponge" layer is also employed above the $0.01 \mathrm{mb}$ level $(\sim 80 \mathrm{~km})$ in order to prevent the reflection of upward propagating waves at the model upper boundary. Although not particularly realistic, the sponge layer can be regarded as a crude representation of GW drag in the mesopause region above $80 \mathrm{~km}$. In fact CMAM data up to $88 \mathrm{~km}$ are used, as the tidal phases continue to be smoothly and realistically varying from $80-88 \mathrm{~km}$ (Manson et al., 2001).

CMAM data used in this paper consist of horizontal winds sampled every $20 \mathrm{~min}$. Data are archived on 15 pressure levels between 60 and $90 \mathrm{~km}$, for a nominal vertical resolution of approximately $3 \mathrm{~km}$. Results for the months of January, April, July, and October only are highlighted here; and these involve 30 day sequences of continuous data.

\section{The MFR systems and data}

The initial analysis applied to the radar data is the fullcorrelation analysis (FCA) for spatial antenna systems. The variant developed by Meek (1980) is used for the more northern stations (Troms $\varnothing 70^{\circ} \mathrm{N}$, Saskatoon $52^{\circ} \mathrm{N}$, London $43^{\circ} \mathrm{N}$, Urbana $40^{\circ} \mathrm{N}$ ) partly due to its usefulness in dealing with correlograms that are noisier or multi-peaked; while a more classical Brigg's method is used at the other stations (Isler and Fritts, 1996): Wakkanai $45^{\circ} \mathrm{N}$, Yamagawa $31^{\circ} \mathrm{N}$, Hawaii $22^{\circ} \mathrm{N}$, Christmas Island $2^{\circ} \mathrm{N}$. Comparisons have shown no significant differences exist between these methods (Thayaparan et al., 1995). The radars provide samples of wind every 2 or $3 \mathrm{~km}$ (ca. $70-100 \mathrm{~km}$ ) and 2 or $5 \mathrm{~min}$ on a continuous basis.

It should be noted that very thorough comparisons exist between winds and tides measured by the MFR and other ground based systems: MWR (Meteor Wind Radar) and MFR radars at $40^{\circ} \mathrm{N}$ (Hocking and Thayaparan, 1997); MFR and Fabry-Perot Interferometers ("green line" and hydroxyl) at $52^{\circ} \mathrm{N}$ (Manson et al., 1996; Meek et al., 1997); and MFR, EISCAT (European Incoherent Scatter) and VHF radars (Manson et al., 1992) at $70^{\circ} \mathrm{N}$. In all of these studies the phases of the tides or directions of the winds have been quite satisfactorily consistent once the system-differences were considered; e.g. differences in data-yield with respect to local time. The amplitudes of tides or wind speeds were in good agreement (typically within 10\%) in some cases, e.g. the optical and radar comparisons, but not in others. In particular, at $70^{\circ} \mathrm{N}$, the tidal amplitudes and wind speeds from the MFR were 0.65 of those from the VHF radar and rockets $(80-90 \mathrm{~km})$. This result is similar to the differences found between HRDI-UARS and MFR systems; e.g. at Saskatoon the MFR speeds are $0.70-0.8$ of those from HRDI (Meek et al., 1997). Also, a recent MFR-MWR comparison at Saskatoon showed ratios of 0.85 (Meek and Manson, Private communication, 2000). As the reason for these ratios is not fully understood at present, we will simply bear this in mind when later comparisons are made in this paper.

A common analysis has been used at each radar location to obtain the amplitudes and phases of the monthly diurnal and semi-diurnal oscillations in the wind field. For each month of available years (1989-1996), an harmonic analysis was applied to the entire 28-31 day time series of hourly values (zonal, E-W; meridional, $\mathrm{N}-\mathrm{S}$ ), for the 12 and $24 \mathrm{~h}$ oscillations (amplitude and phase), to better compare with a modelled month. We required that, for each fit, there were data for $16 \mathrm{~h}$ or more of the 24 possible for each height over the month; also weighted the hourly means in the fit according to the number of values therein. Values of the monthly amplitudes and phases from the completed fits were retained when the standard deviations (sd) of the phases were less than 2.5 and $5 \mathrm{~h}$, respectively; these were obtained from the variances of the least-squares-fits (harmonic analysis). The restriction on the sd was used as a measure of the quality of the fit; this particular choice eliminates noise and provides smoothly varying phases profiles. The minimum height possible to meet these criteria then varied from $70-85 \mathrm{~km}$ while the maximum height was restricted to values below the local estimates or calculations of total reflection of the radar pulse. This latter is generally between $90-100 \mathrm{~km}$. A similar analysis was applied to wind time-sequences (Sect. 2) from CMAM for Sect. 6.

The intention of the data presentations is to focus upon the main features of agreement or disagreement between the observations and the models and also to show the global structures of the tides. These comparisons serve as a further eval- 

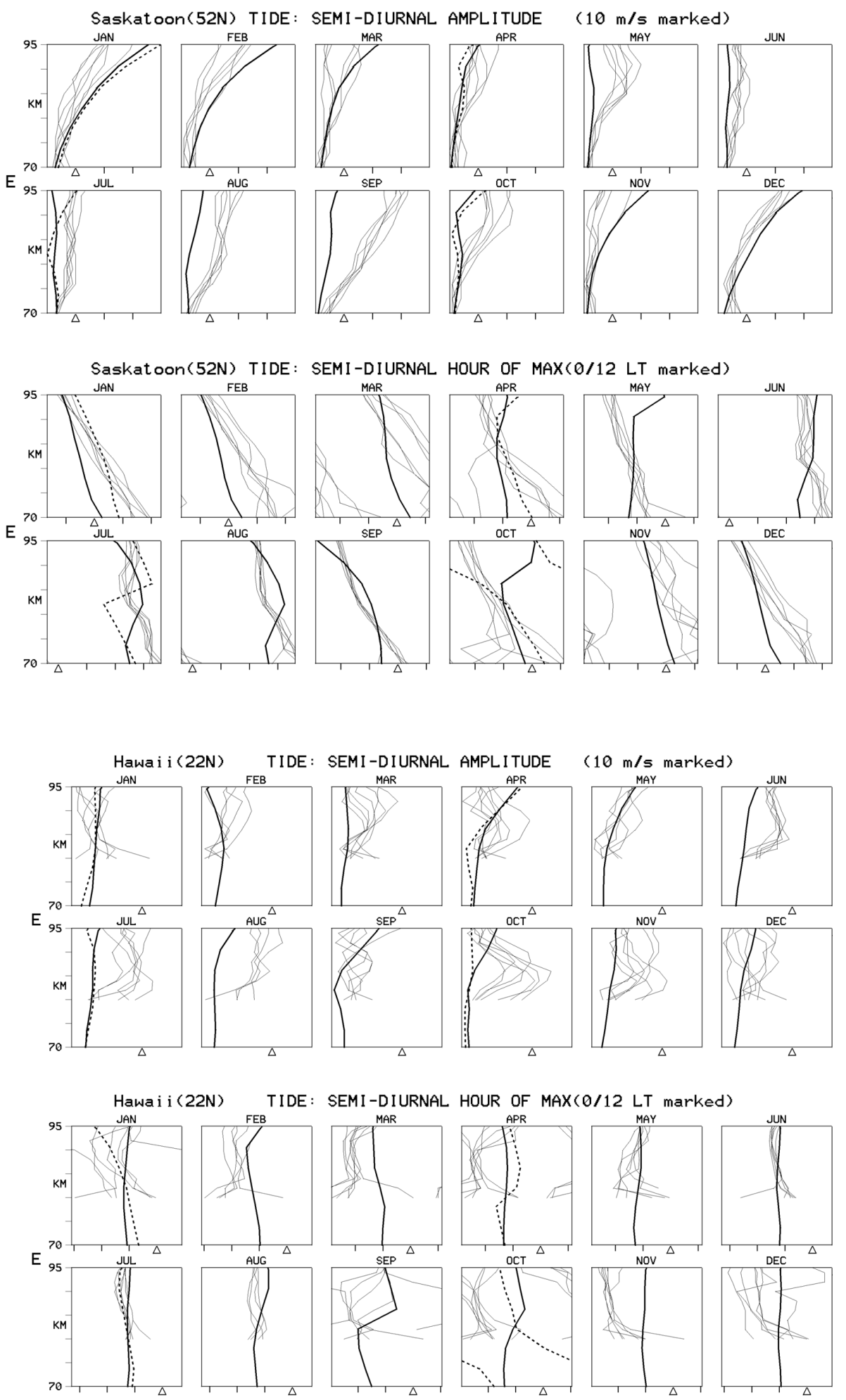

Fig. 1. Profiles of the Semi-Diurnal $(12 \mathrm{~h})$ Tide amplitudes and phases for the zonal $(E)$ component at Saskatoon. The thin lines are for the 6 years of MFR data, the dashed lines for GSWM (original 1995) and the thick lines for GSWM2000. The triangles on the amplitude plots refer to the $10 \mathrm{~m} / \mathrm{s}$ values. For the phase plots the total phase displayed is $12 \mathrm{~h}$; the triangles are at 00:00 and 12:00 LT and their positions are chosen to minimize the number of phase discontinuities ("wrap-around").
Fig. 2. Profiles as for Fig. 1, but for Hawaii. uation of GSWM2000. The figures have been designed to provide easy appreciation of these features. In Sects. 4 and 5 we shall show some monthly MFR profiles for high and low latitudes where the semi-diurnal and diurnal tides, respectively, are dominant and add to those the GSWM profiles. Then, for the $90 \mathrm{~km}$ altitude, latitudinal plots by month are shown for both tides, again with the two models. Finally in those sections we shall show new plots of amplitudes and phase contours as functions of height and latitude, for the middle month of each season. Each data presentation format has a particular advantage and together they provide a very comprehensive test of agreements between models and 
the MFR observations. The last named are valuable in that they show global structure particularly well; it will be seen that differences between GSWM and GSWM2000 are well distinguished in the phase plots. Finally, in Sect. 6, we will show profiles for all stations in the middle months of each season and include the two GSWM and CMAM. As mentioned, CMAM tides are investigated elsewhere (Manson et al., 2001) but this format and the GSWM comparison are new.

\section{Semi-diurnal tides}

\subsection{Monthly profiles; Saskatoon $52^{\circ} \mathrm{N}$, Hawaii $22^{\circ} \mathrm{N}$}

We have chosen to use these two stations where the low and high latitude characteristics of the tidal winds are well displayed. The semi-diurnal $(12 \mathrm{~h})$ tide is significantly larger than the diurnal $(24 \mathrm{~h})$ tide at Saskatoon while the diurnal tide is the larger at Hawaii. The tide is generally circular at both locations, with $3 \mathrm{~h}$ differences between NS and EW components ("quadrature"), so that only one component (EW in the figure) will be shown here. Those readers interested in the larger MFR data set should acquire the full ISAS Report (Manson et al., 1999c). Times shown in the phase-plots are for maximum perturbations in the North and East directions. The individual years of MFR data are not marked to remove confusing detail in Figs. 1 and 2, and the interannual variations will be discussed elsewhere. Generally these variations are modest, indicating that modelling using mean background conditions should approach the median profiles of the up to 7 years of data. The plotting algorithm selects the smallest phase difference between any two heights to minimize 'wrap-around' effects and also the triangle marking 01:00 and 12:00 LT is placed to minimize these effects.

Considering first Fig. 1 for $52^{\circ} \mathrm{N}$, the amplitude observations are smaller than the GSWM models in winter months but otherwise are significantly larger, especially in the spring and autumn. These features were discussed in Paper 1 (Sect. 5) where it was noted that semi-diurnal tropospheric latent-heating effects approach $10 \mathrm{~m} / \mathrm{s}$ in the upper MA (Forbes et al., 1999). Such additional tidal components, while helpful, would not be likely to account for the large equinoctial differences. Otherwise, the $\sim 20 \%$ possible speed bias (MFR small), noted in Sect. 3 for the Saskatoon MFR, would help the winter comparison and worsen that for the rest of the year. The differences between GSWM and GSWM2000 are usually small. Note that the GSWM profiles for each month of each season are constant (and in the figure they are only shown for the middle month of the season), whereas GSWM2000 has unique monthly values. The latter's winter reductions in amplitude are helpful in the comparison.

Moving to the phases, the observations show stable solstitial structures with larger phase slopes (described for convenience as shorter wavelengths) in winter and altitudinally varying slopes in summer;these are strikingly consistent over the two seasons and inter-annually. The phase values for GSWM and GSWM2000 are usually similar to observations in the middle of the sampled heights although the phaseslopes are not very similar to the MFR, e.g. $80 \mathrm{~km}$ vs. $40 \mathrm{~km}$ in winter. It is not clear which model is better overall. However, the summer phase discontinuity of GSWM, which was associated with unobserved short wavelengths at high latitudes, has largely gone in GSWM2000. The observed transitions during the equinoxes are substantial and, although the inter-annual variability is larger in those months, clearly defined monthly phase values and slopes are still evident. Again, while the modelled phases are usually overlapping observations at some heights the phase slopes usually differ. Overall the phases for GSWM2000 are, as a percentage of the 12 frames in Fig. 1, marginally better than the 1995 GSWM version.

Comments on the $22^{\circ} \mathrm{N}$ profiles in Fig. 2 will be brief now that the pattern of commentary has been set. Observed amplitudes are generally larger than the models, especially below $90 \mathrm{~km}$; the decreases above $90 \mathrm{~km}$ may be the MFR speedbias effect. The GSWM2000 values are generally similar to GSWM but the increases in the autumn season come closer to matching the MFR observations. Considering phases, the observed profiles are quite consistent for most months and demonstrate small phase-slopes (wavelengths of about $100 \mathrm{~km}$ ). The modelled phases for both GSWM versions often have similar slopes to those observed although the two models differ in the autumn. Overall, apart from the striking summer agreements in June and July, the observed and modelled phase values differ significantly (often $6 \mathrm{~h}$ or more).

\subsection{Latitudinal plots at $90 \mathrm{~km}$}

These plots allow multi-latitude comparison of amplitude and phase, again for the EW component (Fig. 3); the NS plots (not shown) are very similar and add little to the study. The phase structures can be inferred to a degree from the inverse of the phase-slope, which we abbreviate as an effective wavelength. Although the slopes are calculated over a $6 \mathrm{~km}$ interval near $87 \mathrm{~km}$, the wavelength values usually agree with the characteristics slopes over the $75-95 \mathrm{~km}$ height range evident in Figs. 1 and 2. This was well established in Paper 1.

The amplitude plots of Fig. 3 show that the earlier profiles for $22^{\circ}$ and $52^{\circ} \mathrm{N}$ were thoroughly representative of the global pictures. Except for the 5 winter-like months (November to March) the middle to high latitude observations are larger than the modelled values with low latitude observations also being larger in summer and autumn. Note that there are two additional MFR locations, at Yamagawa $\left(35^{\circ} \mathrm{N}\right)$ and Wakkanai $\left(45^{\circ} \mathrm{N}\right)$. Their data generally fit smoothly into the existing data. The two sets of GSWM amplitudes are quite similar, although in winter the GSWM2000 values are smaller and closer to the observations. Again the phases mirror Figs. 1 and 2, with values at higher latitudes being within $2-3 \mathrm{~h}$ of the models but differing more frequently at lower latitudes. Generally the differences are large (about 6h) in September and October when the ampli- 

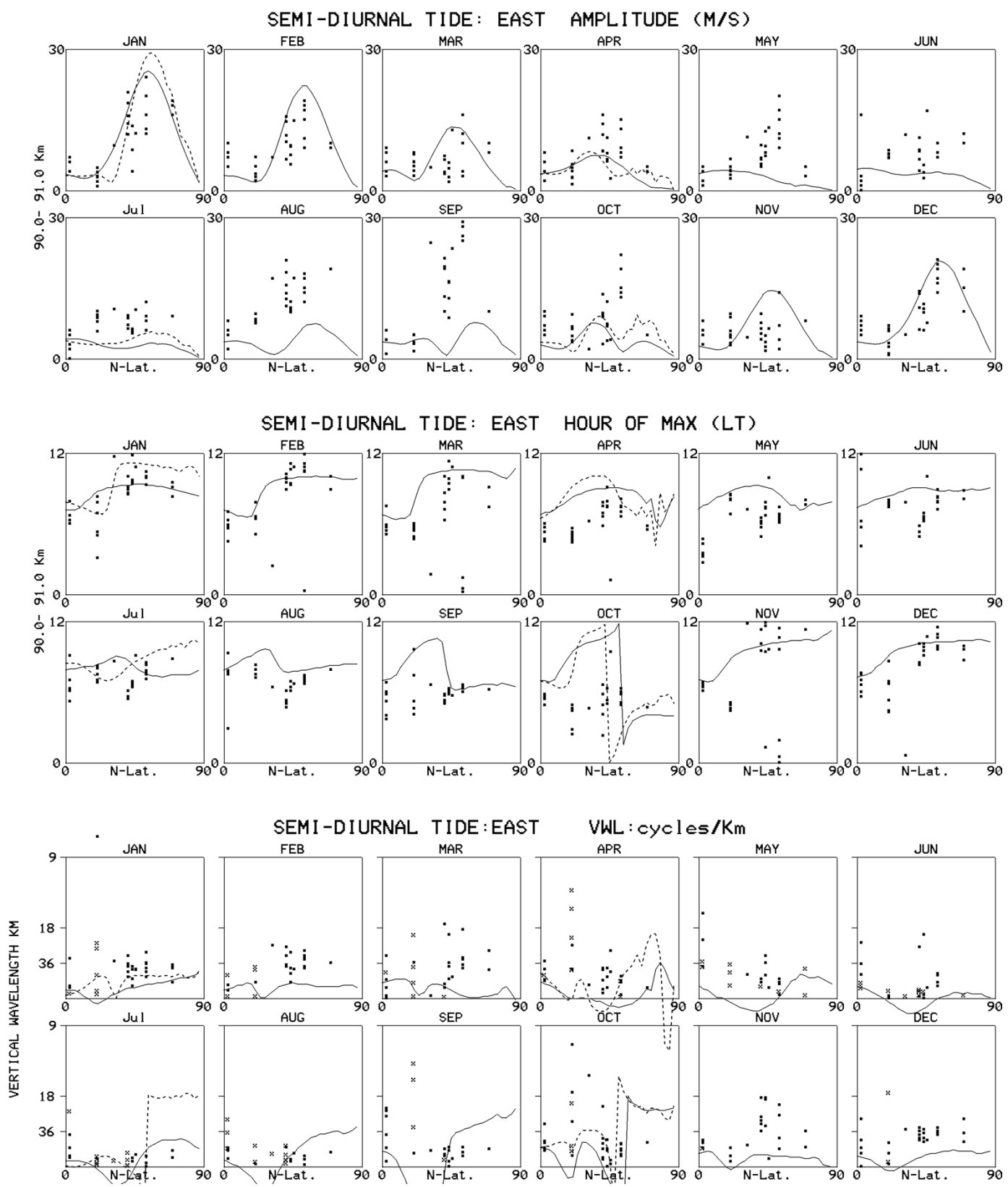

Fig. 3. Latitudinal plots for the zonal (East) component of the Semi-Diurnal ( $12 \mathrm{~h}$ ) Tide near $90 \mathrm{~km}$. The dots are for all of the available years at the MFR locations; these now include Christmas Island $2^{\circ} \mathrm{N}$, Hawaii $22^{\circ} \mathrm{N}$, Yamagawa $31^{\circ} \mathrm{N}$, Urbana $40^{\circ} \mathrm{N}$, London $43^{\circ} \mathrm{N}$, Wakkanai $45^{\circ} \mathrm{N}$, Saskatoon $52^{\circ} \mathrm{N}$, Troms $\varnothing 70^{\circ} \mathrm{N}$. As before, the solid lines are for GSWM and the dashed for GSWM2000. The phase-gradients, interpreted here as vertical wavelengths, are over $6 \mathrm{~km}$ centred on $87 \mathrm{~km}$.

tudes also differ substantially; this suggests substantial differences in the tidal Hough-mode composition in this season. Note that, while the phase-agreements near $90 \mathrm{~km}$ may be relatively good, the phase-slopes may differ and thus give poorer phase-agreement at other heights i.e. Fig. 1.

The phase-slopes, converted to an equivalent wavelength, also emphasize the generality of the earlier profiles. Above $22^{\circ} \mathrm{N}$, observed winter wavelengths are smaller (about half, 40 vs. $80 \mathrm{~km}$ ) than modelled whilst, in summer, observed values are long or irregular (the cross indicates a negative slope) which is in good agreement with the models. (In the summer case the combination of small phase gradients and random fluctuations (noise) will have led to some of these negative values; others will be legitimate and relate to superposition of tidal-modes.) This agreement is especially true for GSWM2000 at high latitudes where the problematic short values $(18 \mathrm{~km})$ of the original GSWM version have been avoided. The modelled values in spring are too large and, in autumn, show more latitudinal variability than is observed. Apart from the important summer improvement, GSWM2000 is not significantly different from the original version at latitudes beyond $22^{\circ} \mathrm{N}$. At the lowest latitudes, the 

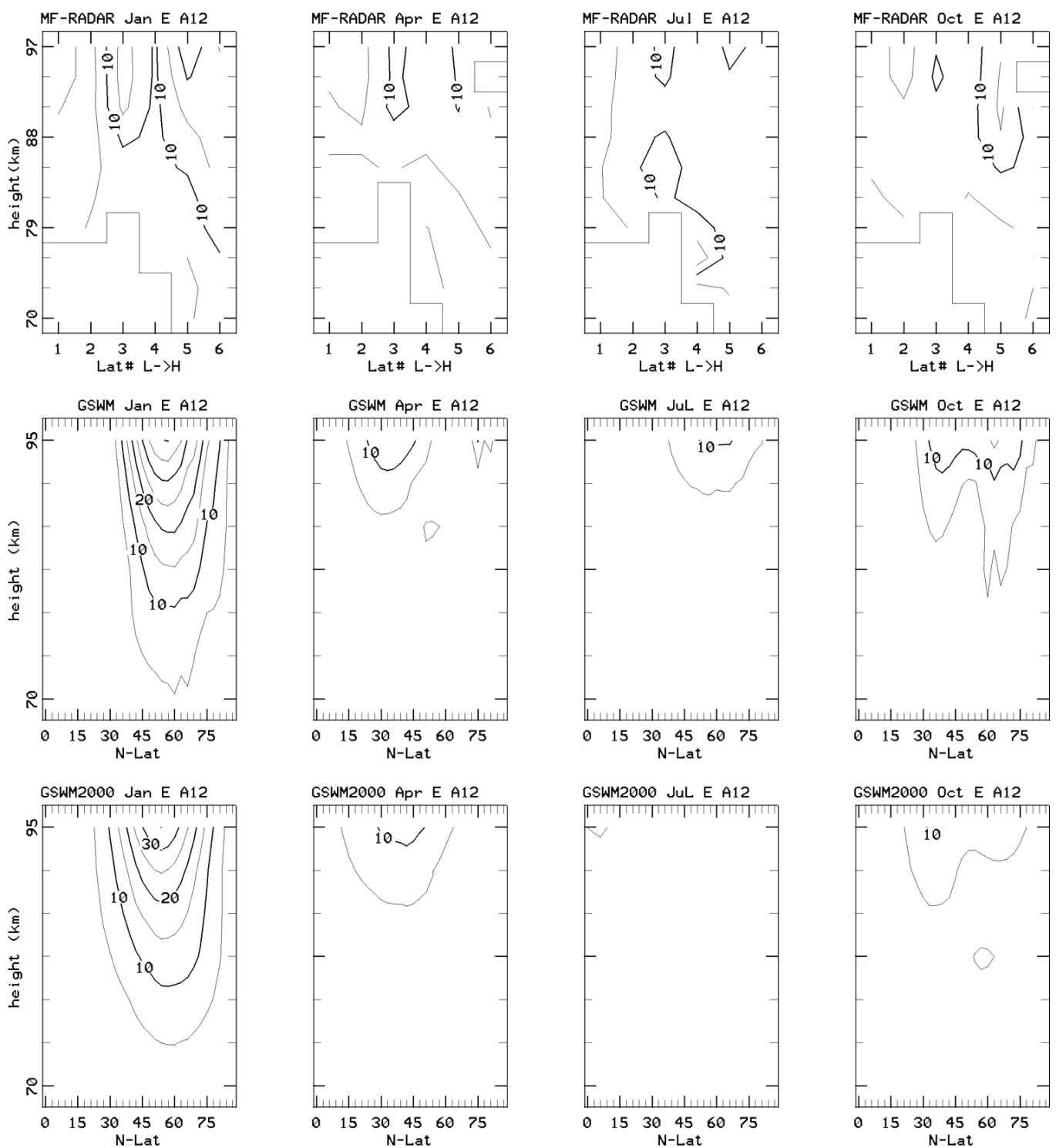

Fig. 4. Amplitude (A12) contour plots for the zonal component of the $12 \mathrm{~h}$ Tide. Plots are shown for the MFR systems (Latitude numbers 1-6; Christmas Island, Hawaii, Urbana, London, Saskatoon and Troms $\varnothing$ ), the GSWM, and the GSWM2000. The numbers on the lines are in $\mathrm{m} / \mathrm{s}$; +ve meaning toward the east.

Christmas Island $\left(2^{\circ} \mathrm{N}\right)$ observations are often similar to the models and, at Hawaii $\left(22^{\circ} \mathrm{N}\right)$, observed and modelled values are often large or negative.

\subsection{Contour plots: height versus latitude}

The new EW contour plots (Figs. 4 and 5) very nicely summarize the above comparisons (The NS are very similar). The model values are plotted versus latitude; the radar locations (shown as numbers $1-6)$ are at Christmas Island $\left(2^{\circ} \mathrm{N}\right)$, Hawaii $\left(22^{\circ} \mathrm{N}\right)$, Urbana $\left(40^{\circ} \mathrm{N}\right)$, London $\left(43^{\circ} \mathrm{N}\right)$, Saskatoon $\left(52^{\circ} \mathrm{N}\right)$ and Troms $\varnothing\left(70^{\circ} \mathrm{N}\right)$. These are reasonably evenly spaced, except for the two sites near $40^{\circ} \mathrm{N}$, and for these small-scale contour plots model-radar comparisons are quite straight-forward. Although absolute comparisons of values are less obvious, the tidal structures are ideally displayed (Here the new $31^{\circ}$ and $45^{\circ} \mathrm{N}$ data are not incorporated as they are from one year only, while 7 years are used for the other MFR systems to form means). The amplitudes are arithmetic means of the annual-monthly values. In Fig. 4 the modelled higher latitude large-amplitude cell of winter is very clear; and, as expected from Fig. 3, the observed January month also shows a maximum, albeit somewhat weaker. However, it is clear from the annual profiles and $90 \mathrm{~km}$ values (Figs. 1 and 3 ) that values approaching those of the model do occur in some years. Given that the phase-slopes also differ (Fig. 5) it is clear that a particular tidal Hough-mode in the model has been amplified. The observed phase structures for the four months generally vary quite smoothly although, in the equinoxes, there are a few localized regions with strong 

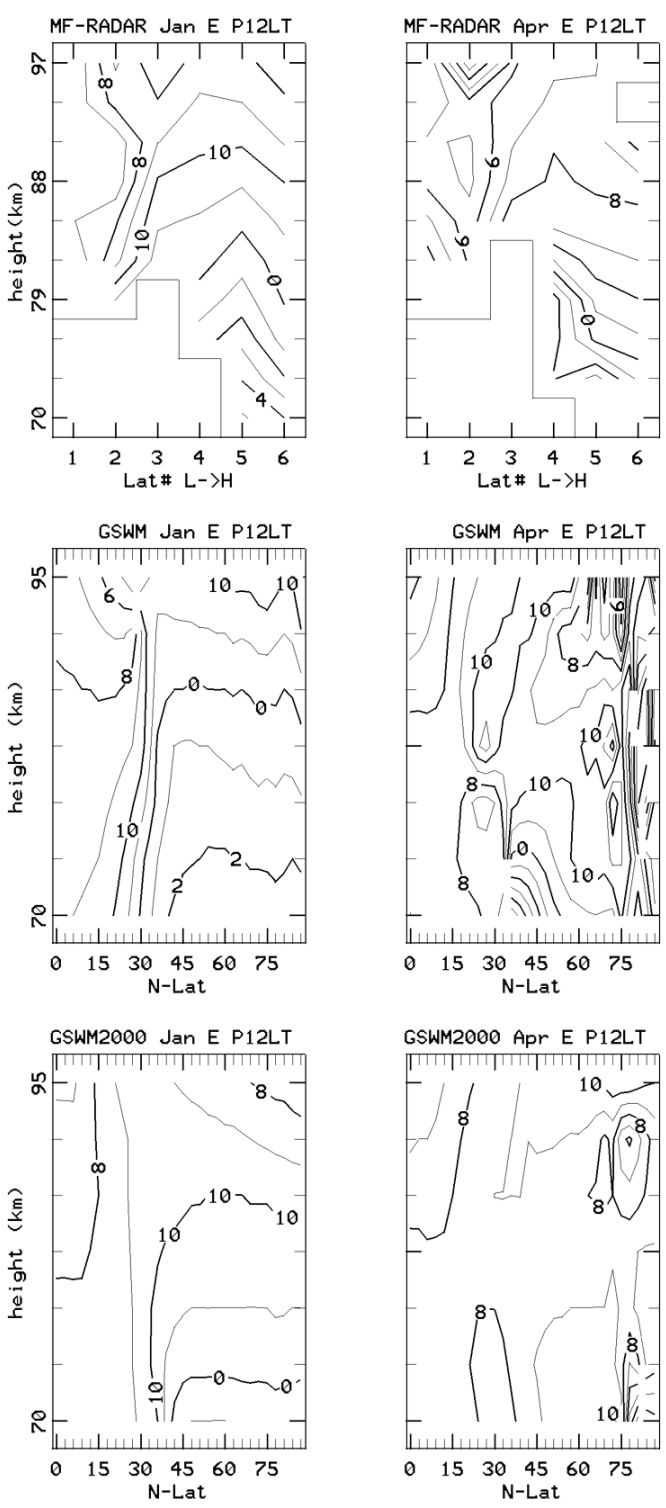
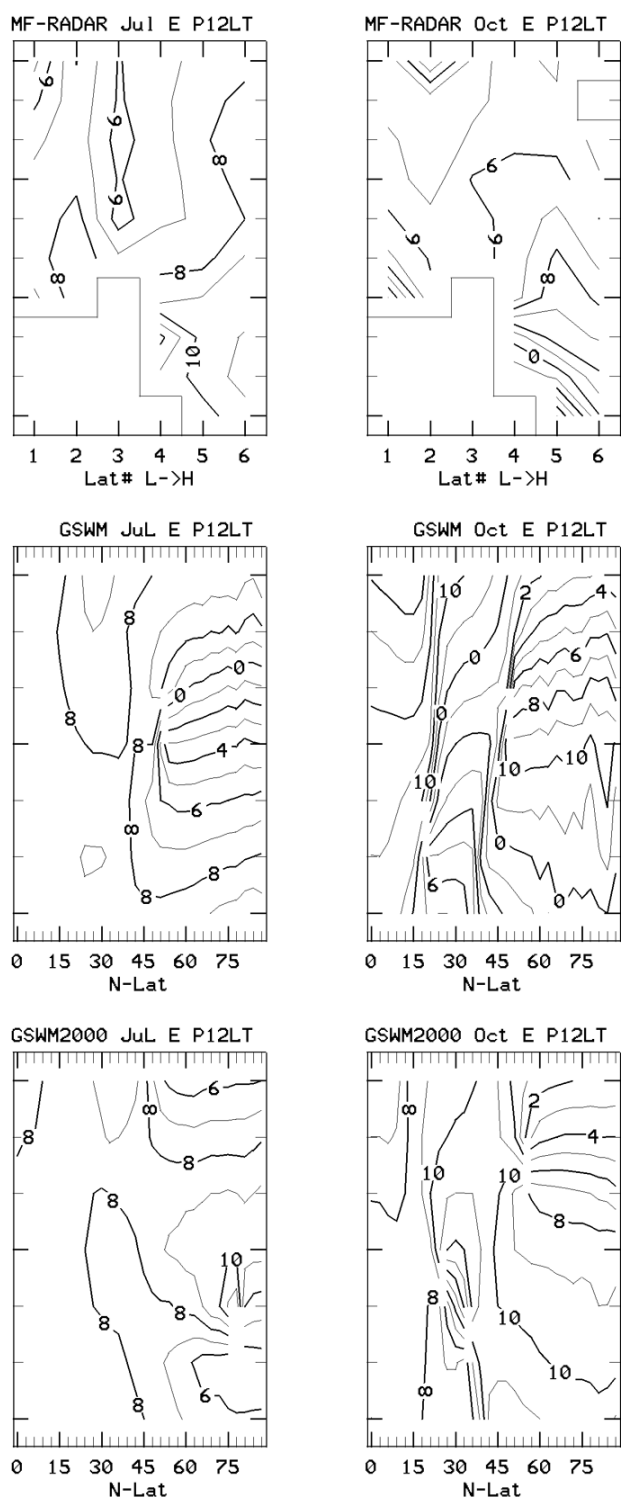

Fig. 5. Phase (P12) contour plots for the 12 Tide. Otherwise, as in Fig. 4. The numbers on the lines are for the time of maximum eastward wind $(+v e)$.

shears which are due to the variability of the season, local tidal structures and data points of greater uncertainty. Nevertheless, wavelengths are consistently longer/shorter at low/high latitudes, except that summer has shorter/longer values at lower/upper heights at mid-latitudes (Fig. 1). The models also generally demonstrate shorter wavelengths at higher latitudes. Without going into detail, because the comments of Sects. 4.1 and 4.2 are generally appropriate here, the GSWM2000 structures are clearly preferable to the GSWM, especially in spring and summer. However, the vertical phase gradients in the two GSWM versions differ clearly from the observations.

In conclusion, while GSWM2000 is a modest improvement for the semi-diurnal tide, significant differences still remain in modelled amplitudes and overall phase-structures with the Pacific-North American sector MFRs. Neither GSWM may be said to model the semi-diurnal tide well. As noted earlier, additional tidal components forced by tropospheric latent heat release may improve the GSWM capabilities. Also, GSWM may be missing a fundamental migrating tidal component. It should also be remembered that the observed oscillations will potentially contain nonsolar-migrating tidal components. Measurements of longitudinal variations in tidal characteristics are thus very valuable. The most useful assessment is by Jacobi et al. (1999), who showed that, while the semi-diurnal tidal phase structures near $52^{\circ} \mathrm{N}$ were very similar between $4^{\circ} \mathrm{W}-49^{\circ} \mathrm{E}$ and $107^{\circ} \mathrm{W}$, the amplitudes in winter and autumn were doubled at $49^{\circ} \mathrm{E}$ and $107^{\circ} \mathrm{W}$ compared with Western Europe and that the Saskatoon values were never the smallest of the 

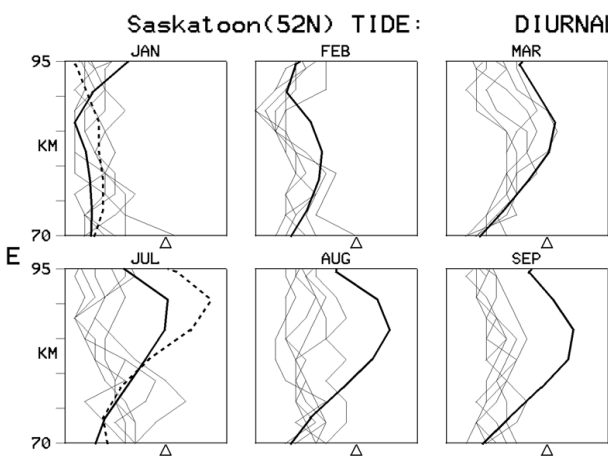

SEP
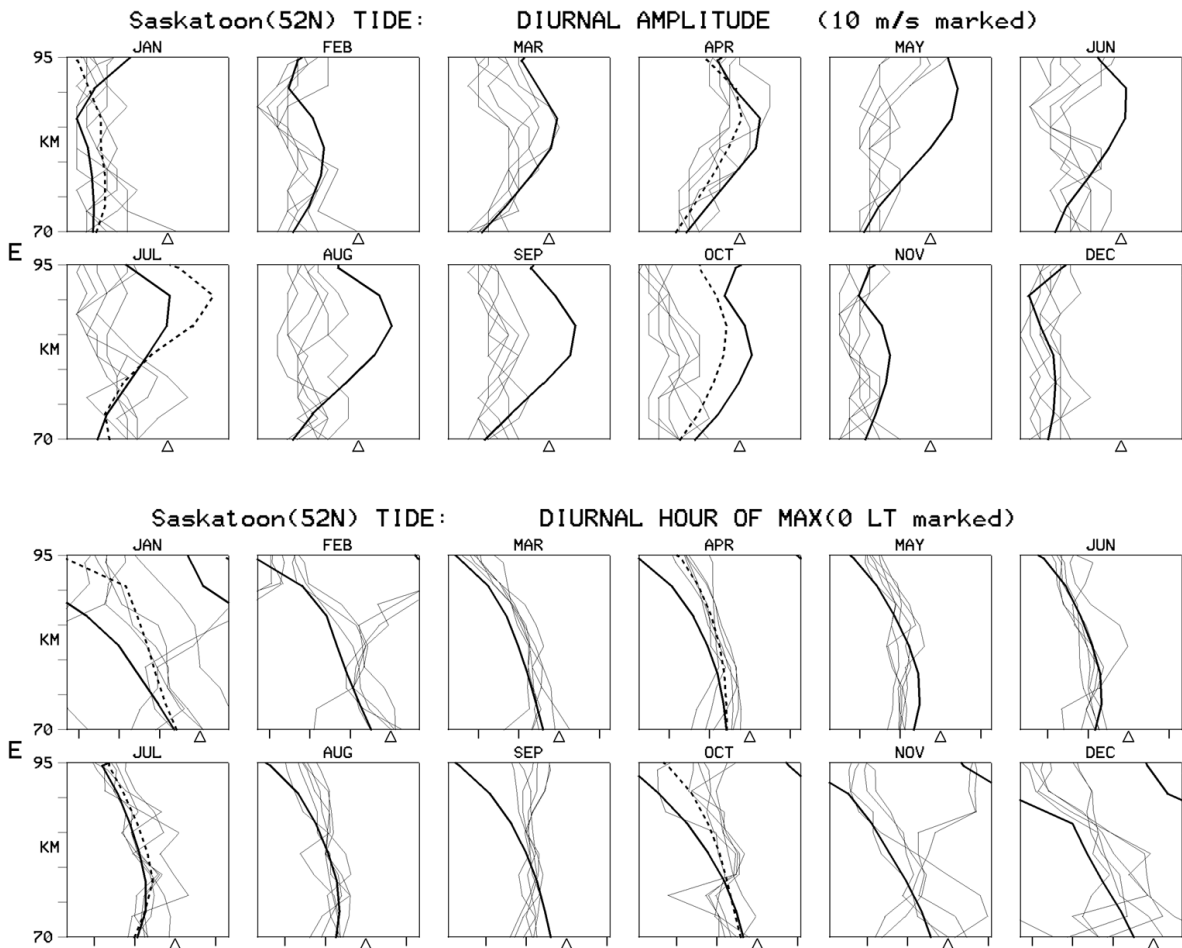

DIURNAL HOUR OF MAX(O LT marked)
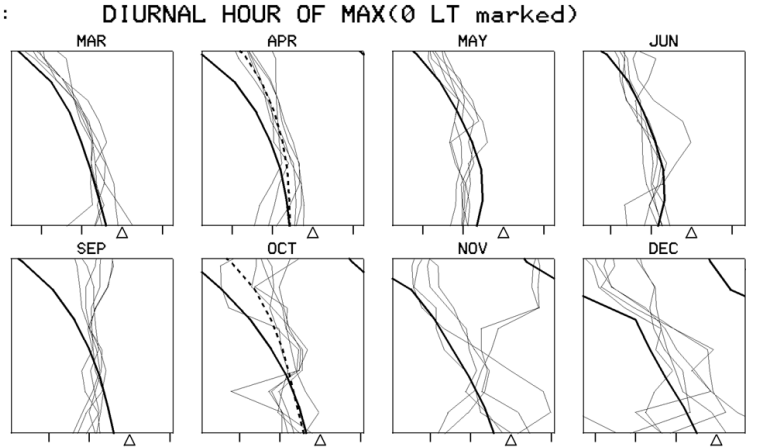

Fig. 6. Profiles of the Diurnal $(24 \mathrm{~h})$ Tide amplitudes and phases for the zonal $(E)$ component at Saskatoon. The thin lines are for the 6 years of MFR data, the dashed lines for GSWM (original 1995) and the thick lines for GSWM2000. The triangles on the amplitude plots refer to the $10 \mathrm{~m} / \mathrm{s}$ values. For the phase plots, the total phase displayed is $24 \mathrm{~h}$; the triangles are at 00:00 LT and their positions are chosen to minimize the number of phase discontinuities ("wrap-around").
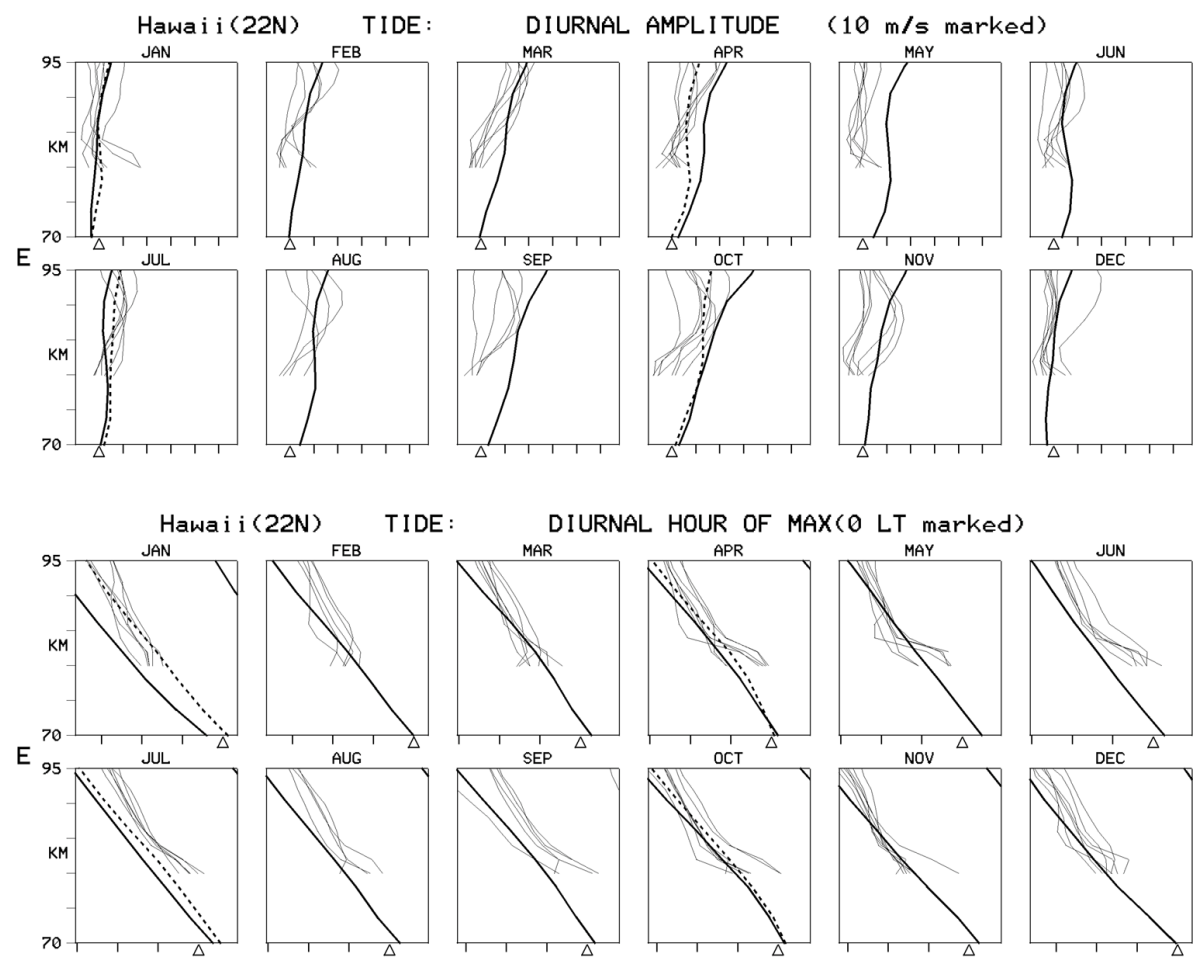

Fig. 7. Profiles as for Fig. 6, but for Hawaii.

longitudinally-varying data set. Similar longitudinal variations in amplitude where shown in the summer months of 1999 by Pancheva et al. (2001).

We make a brief comment on the comparisons between radar and GSWM2000 tidal winds by Pancheva et al. (2001).
These were for a 3-month summer (June-August) campaign in 1999 with 15 northern hemisphere radars. Results were restricted to heights near $90 \mathrm{~km}$. Thus, comparative figures were restricted to the style of Figs. 3 and 8, with latitudinal plots of amplitudes, phases and phase gradients (inferred 
DIURNAL TIDE: EAST AMPLITUDE (M/S)
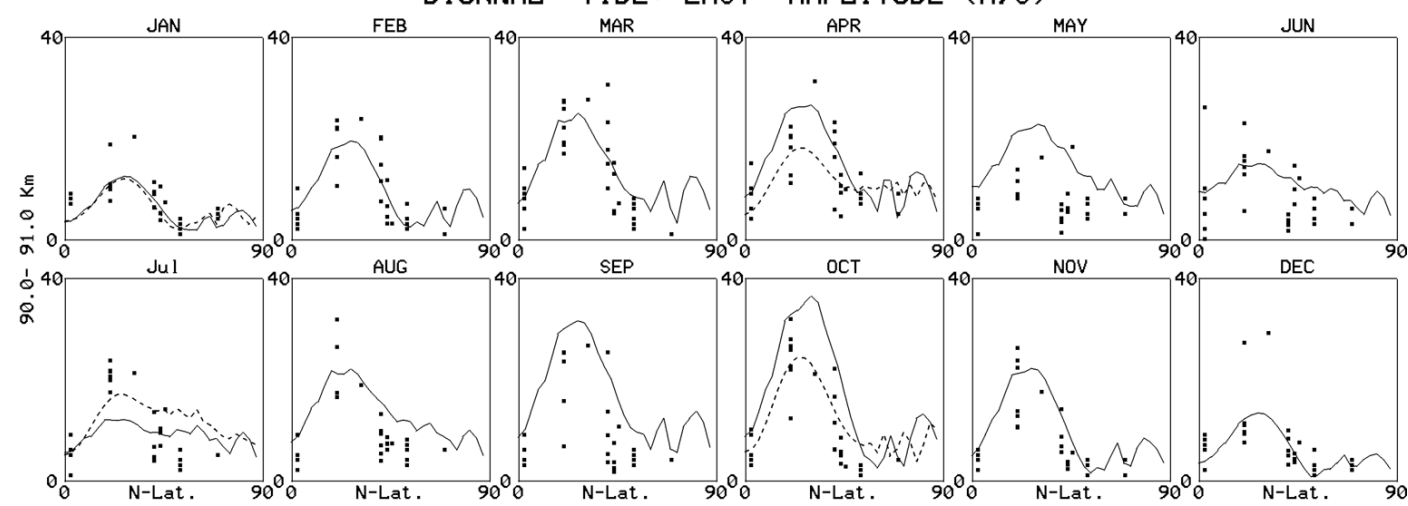

DIURNAL TIDE : EAST HOUR OF MAX (LT)
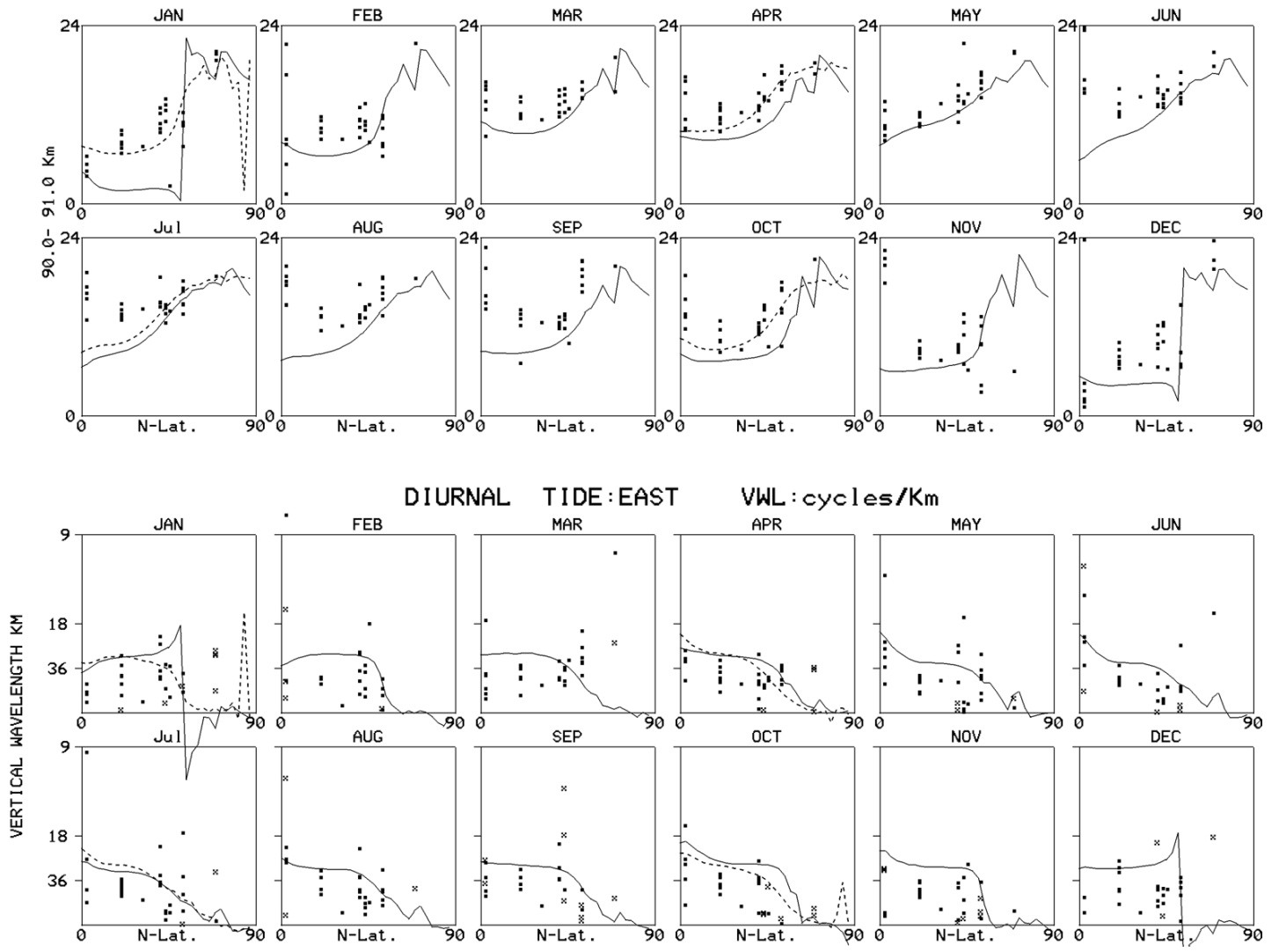

Fig. 8. Latitudinal plots for the Diurnal Tide $(24 \mathrm{~h})$ near $90 \mathrm{~km}$. Otherwise as for Fig. 3.

vertical wavelengths). Where possible, latitudinal averages of radar data were used but only latitudes near $50^{\circ} \mathrm{N}$ allowed for significant smoothing of any longitudinal variability. The phase and amplitude height structures revealed by our Figs. 1, 2, 4 and 5 (and our subsequent figures for the diurnal tide) were not available from their observations, nor was the GSWM2000 assessed in that fashion, e.g. our Figs. 4 and 5. However, the results shown by Pancheva et al. (2001) are very similar to those shown in Fig. 3 and discussed above, consistent with several of the radars contributing data to both studies and the modest inter-annual variability shown in our figures.

\section{Diurnal tides}

\subsection{Monthly profiles; Saskatoon $52^{\circ} \mathrm{N}$, Hawaii $22^{\circ} \mathrm{N}$}

We shall follow the same pattern of presentation as in Sect. 4 . The models and observations for Saskatoon show similar amplitudes and profile shapes in winter and spring (Fig. 6), while in summer-like months and autumn the models are larger. The equinoctial values for GSWM2000 are larger than the original GSWM, due to the new GW stress, but are smaller in summer months. These mid-latitude differences between model and MFR are probably real, as the possible 

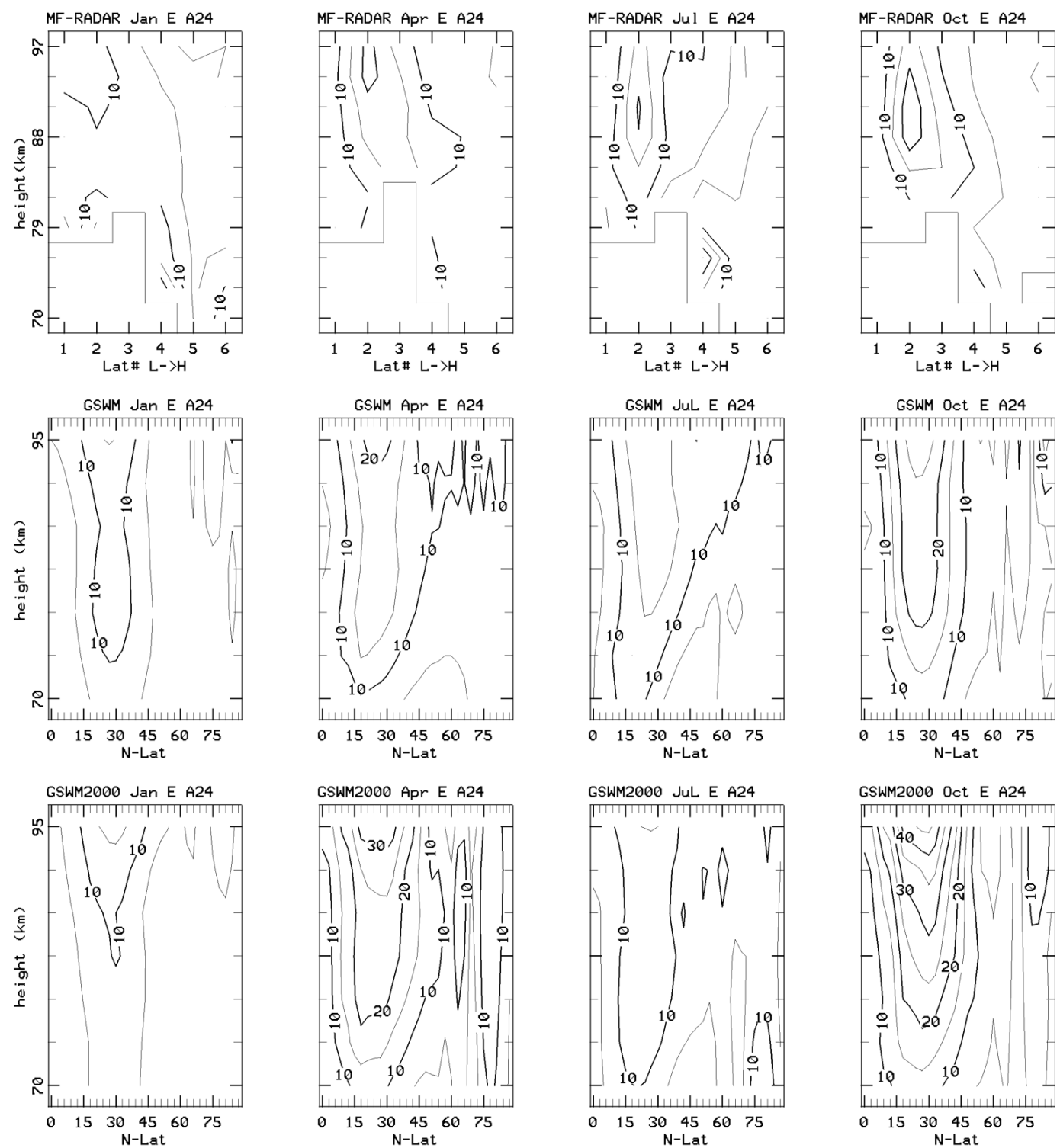

Fig. 9. Amplitude (A24) contour plots for the zonal component of the $24 \mathrm{~h}$ Tide. Otherwise as for Fig. 4.

MFR speed bias factor (reductions) is only circa $20 \%$ below $90 \mathrm{~km}$. Also, the observed phase structures are remarkably consistent inter-annually and by month, although the winter months are more variable, probably due to planetary waves and stratospheric warmings (STRATWARMS). As discussed in Paper 1, the phase-agreement with GSWM is remarkably good in all months, and represents the first successful modelling of non-winter months at mid-latitudes. As expected GSWM2000 is consistent with GSWM, but it does show a consistent phase-offset.

Figure 7 shows the data from Hawaii. The modelled and observed amplitudes are quite similar in winter and summer but, in the equinoxes, the modelled values, especially GSWM2000, lie just beyond the observed ranges of values. The new model is again larger than the original GSWM. However allowing for a possible 20\% MFR speed bias, which generally increases with height, the agreement would be satisfactory. The observed phases are consistent by month and year and the agreement with modelled values, possibly between 85 and $90 \mathrm{~km}$, is generally good (phase differences are generally less than $3 \mathrm{~h}$ ). However, the observed wavelengths are generally larger than modelled, especially in winter. And again, usually the GSWM2000 is further away from the data than is GSWM.

The EW amplitude plots of Figs. 6 and 7 were quite representative of the entire low and mid-to high latitude characteristics (Fig. 8). The new data for $31^{\circ} \mathrm{N}$ and $45^{\circ} \mathrm{N}$ are generally consistent with neighbouring latitudes. Apart from the previously mentioned smaller values observed in summer and autumn at higher latitudes, the agreement with the models is very good. However, the otherwise desirable increase in equinoctial amplitudes in GSWM2000 moves the curves 

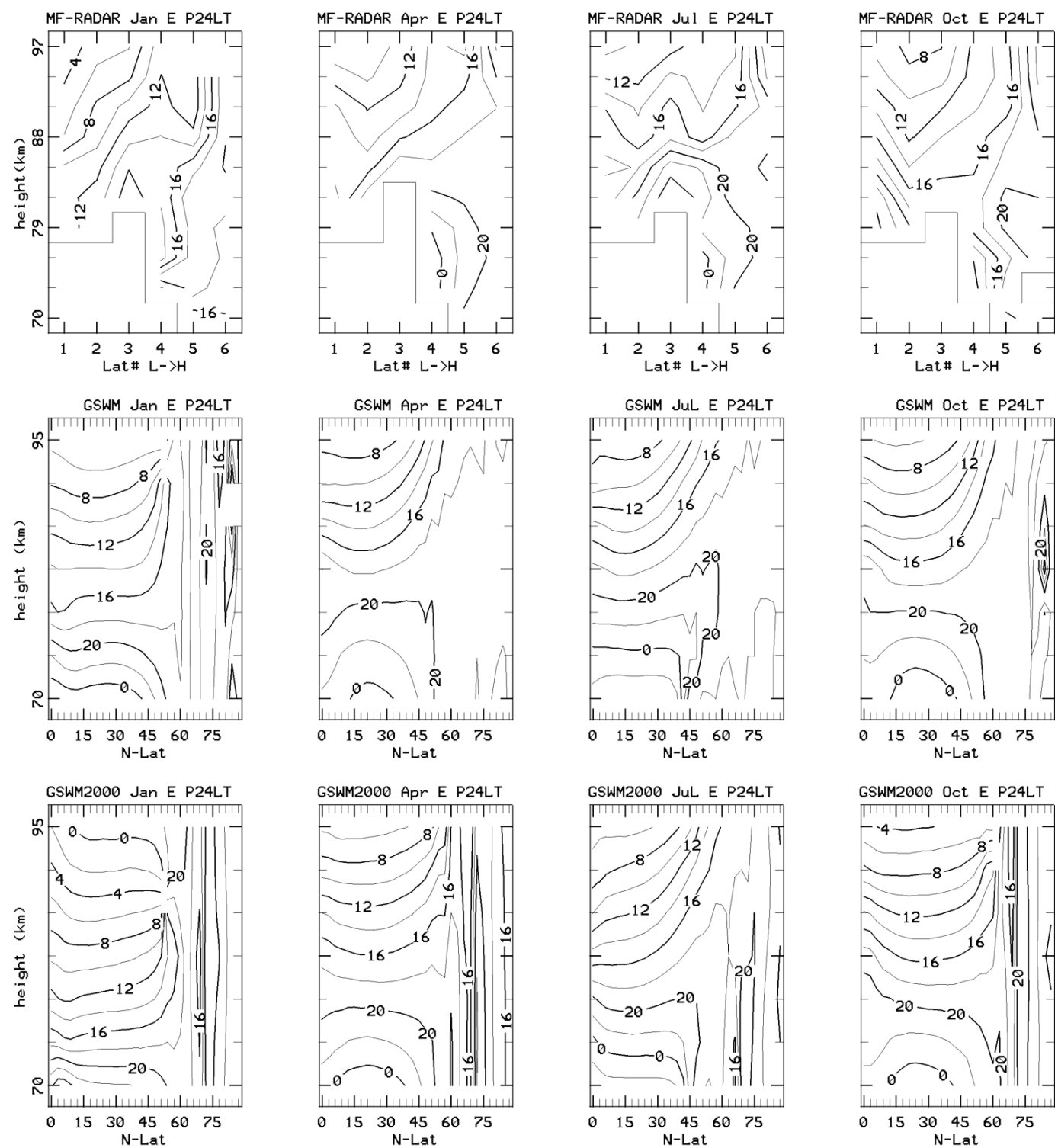

Fig. 10. Phase (P24) contour plots for the $24 \mathrm{~h}$ Tide. Otherwise as for Fig. 9.

away from the data, a trend probably compensated for by the probable MFR's speed bias. The NS plots (not shown) are generally similar, except in the equinox where low latitude GSWM2000 peak values are always larger (by a factor of two) than observed. Considering the phases, the agreement of observations with GSWM is excellent at $90 \mathrm{~km}$ (see Paper 1 for detailed discussions) but with the tendency for the low-latitude model values to lead the observations (also Fig. 7). Also, the new model's phases are generally in poorer agreement by $2-3 \mathrm{~h}$ due to a consistent offset. Considering the complexity of mid-latitude diurnal tides, this generally close agreement with the original GSWM is remarkable while that with the new model is not representative of the data despite new and desirable features in the new version (Sect. 2).

Finally, considering the corresponding wavelengths, Fig. 8 provides generalization of the profile results of Figs. 6 and 7 . Thus at mid-latitudes throughout much of the year, the modelled wavelengths are smaller than observed, especially for GSWM2000; and at low latitudes, and especially for Hawaii, the modelled values are also smaller. This latter effect was noted earlier in comparisons between observed HRDI and MFR winds (Burrage et al., 1996), and has not been resolved. Differences between the two models are small, with GSWM being closer to observations in 6 months of the year.

\subsection{Contour plots: height versus latitude}

The amplitude (EW) contours (Fig. 9) show the modelled low-latitude equinoctial maxima very clearly; although the observations match GSWM quite well they are smaller than the new model version. It is particularly desirable that lowlatitude radar observations be extended down to $70 \mathrm{~km}$ to 


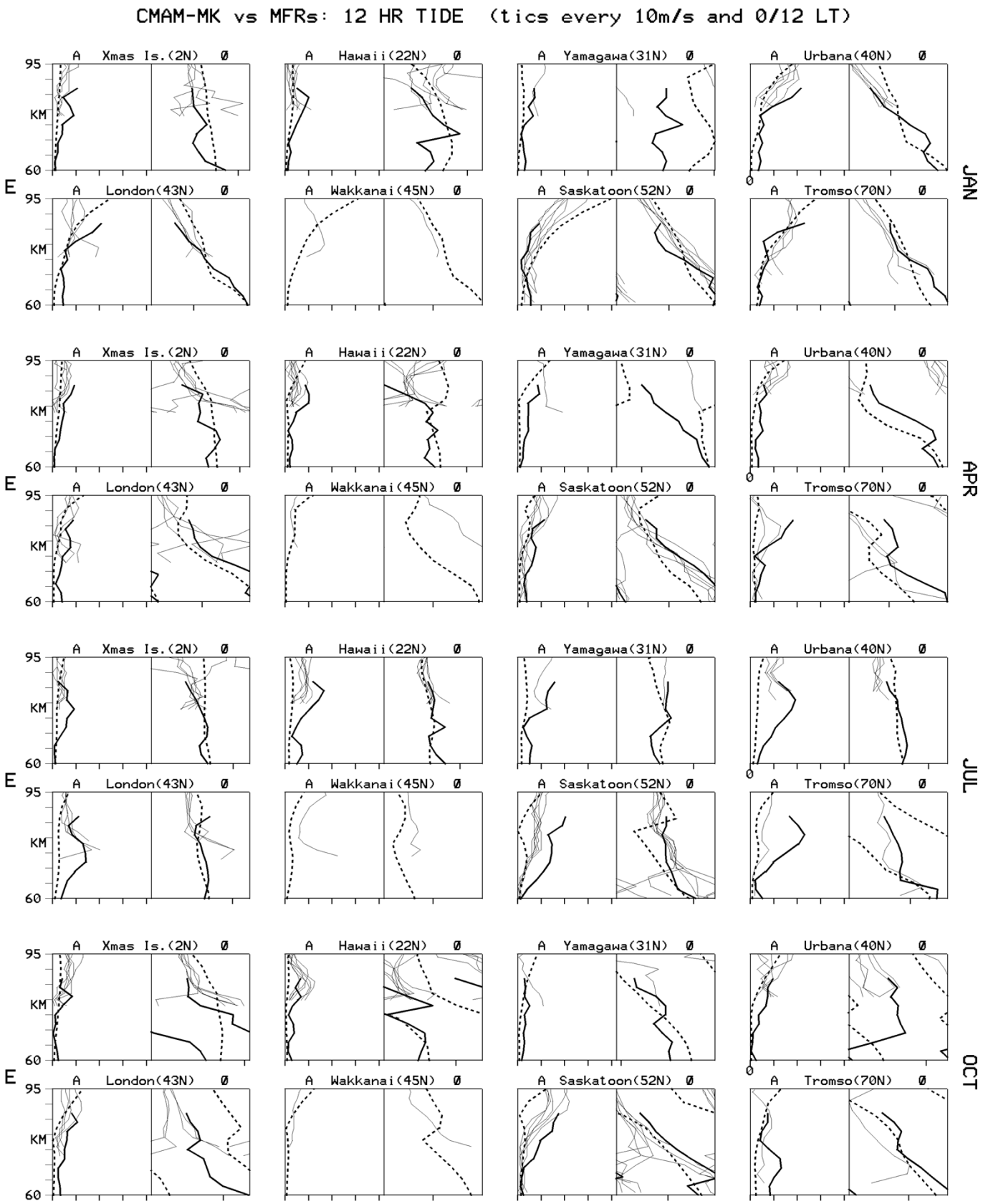

Fig. 11. Comparisons between profiles for the Semi-Diurnal (12h) Tide amplitudes and phases from the 8 MFR systems (thin lines), the Canadian GCM (CMAM) with the thick lines and the GSWM (thick dashed lines). The monthly means for winter, spring, summer and autumn (central) months are shown.

check the very large modelled values there. As mentioned in Sect. 5.2, the modest MFR speed-bias would minimize these differences. In other seasons, modelled amplitudes are rather similar to observations although, as noted in Figs. 6 and 8 , the modelled values at middle latitudes are usually larger (10 vs. $5 \mathrm{~m} / \mathrm{s}$ ) than observed even if an MFR bias correction is applied. Observed phase structures (Fig. 10) vary quite smoothly with height and latitude, providing vertical phase-slopes consistent with shorter wavelengths (ca. 35$40 \mathrm{~km}$ ) at low latitudes and longer (evanescent to $50 \mathrm{~km}$ ) at high latitudes $\left(>50^{\circ} \mathrm{N}\right)$. The shortest high-latitude values occur in winter. The two models show this transition between dominant tidal structures very clearly. However GSWM is clearly closer to observations, since for the 2000 version unobserved shorter structures have spread and are dominant at Saskatoon $\left(52^{\circ} \mathrm{N}\right)$ in winter, spring and autumn (as in Fig. 6). It is probable that this extension to higher latitudes is also associated with their larger amplitudes, as mentioned above. In this case the NS component of GSWM2000 (not shown) is also interesting as the short wavelength structures do not 

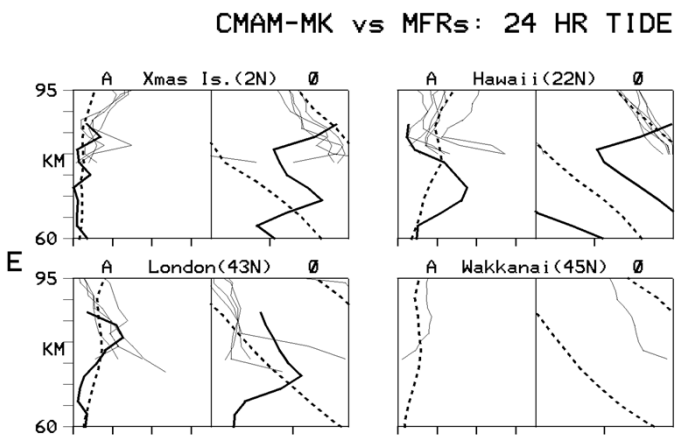

(t ics every $10 \mathrm{~m} / \mathrm{s}$ and $0 \mathrm{LT}$ )
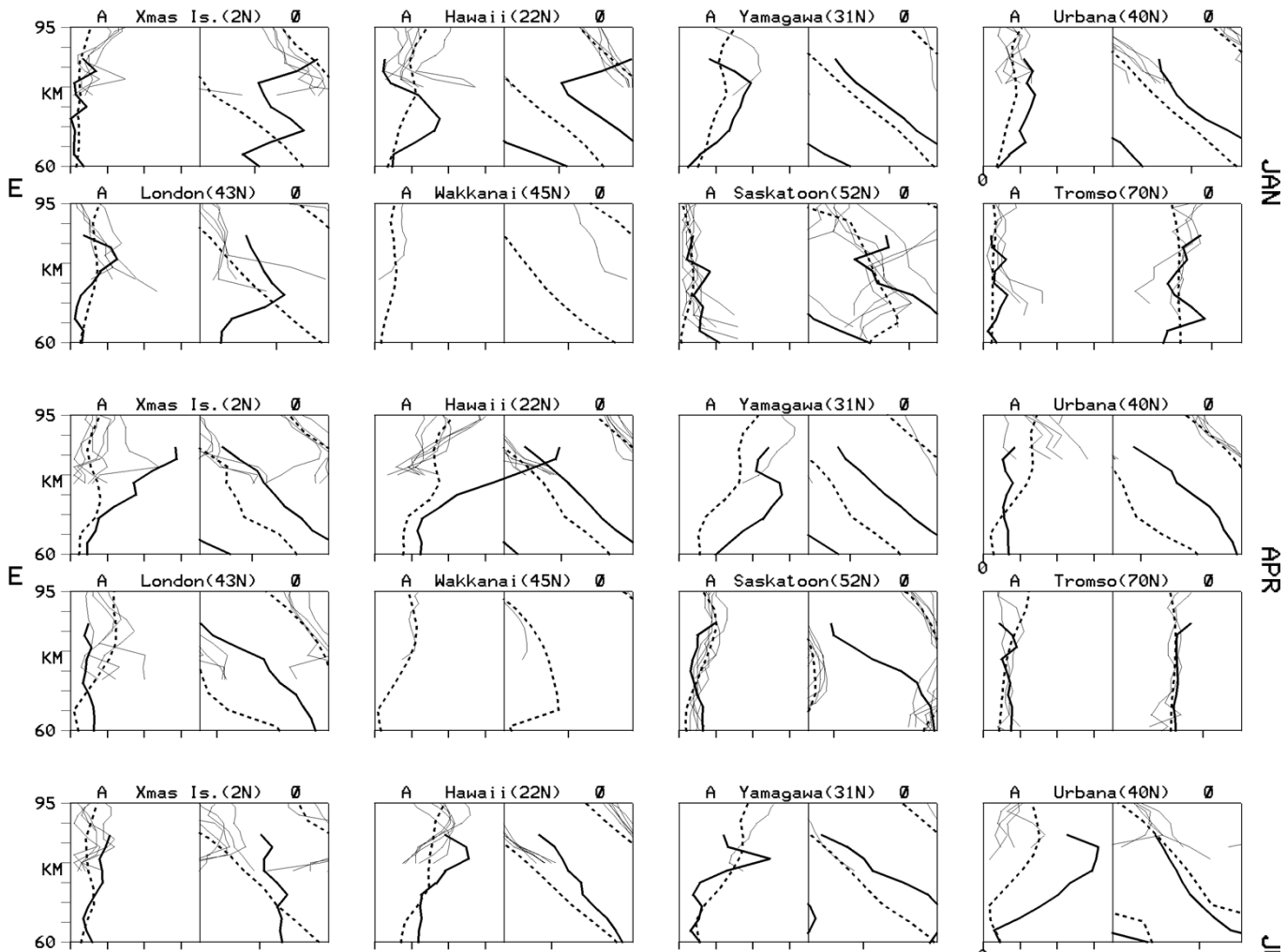

E
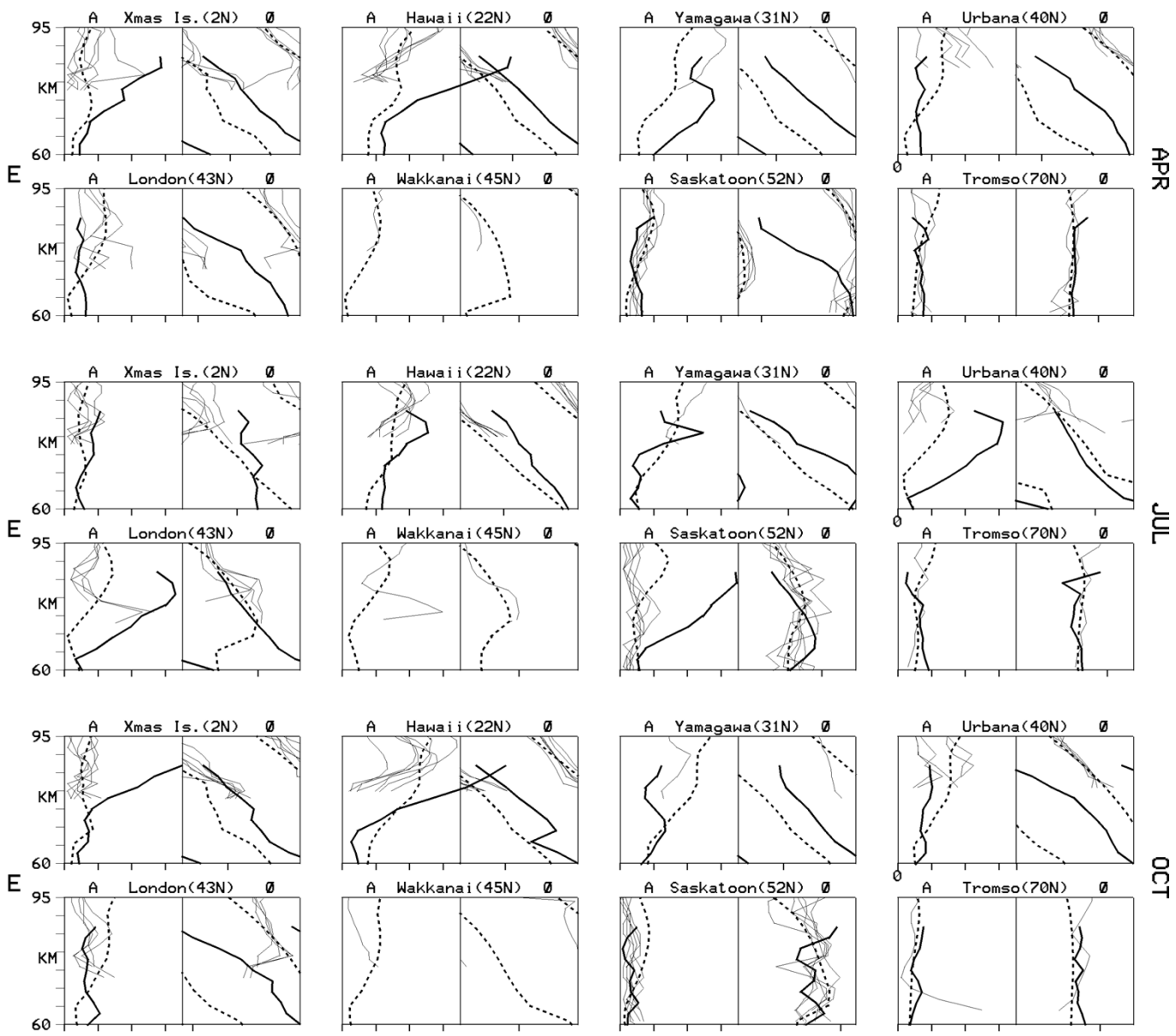

Fig. 12. Comparisons between the Diurnal ( $24 \mathrm{~h})$ Tide profiles for the MFR and GSWM. Otherwise as for Fig. 11.

reach as far north $\left(\sim 5^{\circ}\right.$ difference). This difference between the two components is indeed weakly evident at Saskatoon in the original GSWM version and was discussed in Paper 1. Overall then, and as discussed fully in Paper 1, the original GSWM agrees very well with observations.

In summary, the new model is not an improvement over GSWM, especially with regard to phase structures. As with the semi-diurnal tide, the incorporation of latent heat effects into GSWM versions would provide tidal modes which could, through superposition, modify amplitudes and phases. Again, longitudinal variability of the tides could be responsible for some of the differences between the new model and the observations, rather than the simpler conclusion that GSWM is the better model. Pancheva et al. (2001) show very modest observed summer phase-changes with longitude (near $90 \mathrm{~km}$ ) and larger amplitude changes (a factor of 2); these comparisons were for a latitude range of $43-56^{\circ} \mathrm{N}$, which is broad enough to partly obscure the real variability. However, the amplitudes for the North American-Pacific sector (near $50^{\circ} \mathrm{N}$ ) were larger than for Europe in the summer months which does not help the comparisons in Figs. 8 and 9. The different zonal winds in the two GSWM versions will also be a factor in the different tidal-winds which have been produced. A final thought, which leads directly into Sect. 6, 
Table 1. Percentage of "better" matches

\begin{tabular}{cccc}
\hline & GSWM & CMAM & Models similar \\
\hline 12h SD tide & & & \\
Amplitude & $4 \%$ & $80 \%$ & $16 \%$ \\
Phase & $11 \%$ & $27 \%$ & $62 \%$ \\
24h D tide & & & \\
Amplitude & $56 \%$ & $12 \%$ & $32 \%$ \\
Phase & $73 \%$ & - & $27 \%$ \\
\hline
\end{tabular}

NB: Only $3 \%$ of the cases had neither model close to the observations. (The remaining cases represent the $100 \%$ above.)

is that GW stress or drag and the eddy diffusion effects upon momentum and heat fluxes are not as realistic as desirable. In Manson et al. (2001) the differing effects of two parameterization schemes (Medvedev and Klaassen, 1995; Hines, 1997; Medvedev and Klaassen, 2000, where there are comparative discussions) were shown to have profound implications for hemispheric CMAM amplitude and phase structures. Below we discuss results from the former (MK) scheme in a CMAM experiment.

As for the semi-diurnal tide, we comment briefly on the summer (June-August, 1999) comparisons between radar and GSWM2000 tidal winds by Pancheva et al. (2001), for heights near $90 \mathrm{~km}$. In figures similar to our Fig. 8, they also found very good agreements for amplitudes and phases.

\section{Semi-diurnal and diurnal tides from CMAM}

The time-sequences for the MFR locations were obtained from the CMAM-MK experiment and analysed in identical fashion to the radar data. We have chosen a profile format so that variations with height at the eight latitudinally-varying locations may be studied for amplitude and phase. Contour plots are shown elsewhere (Manson et al., 2001). Inspection of Fig. 11 for the semi-diurnal tide, where thin lines are for the MFRs and thick lines are for the CMAM, shows generally very good agreement at all latitudes and most seasons but with apparently excessive summer CMAM amplitudes at middle to high latitudes and phase disagreements at $31^{\circ} \mathrm{N}$ in winter and spring. The GSWM (thick dashed-line) has been added for comparative purposes and is clearly less similar to the MFR than is the CMAM. We chose GSWM as the semidiurnal tides are similar in both versions but the diurnal tides are closer to observations in that version. The percentages of best-matches are shown in Table 1. The model in "better" agreement with observations is selected at each location and season but, if both models are close to the observations, the "similar" choice is made. Usually one or other model-profile passes through the data at several heights. In only two or three cases out of 60 does neither model satisfy these conditions for "similar" or "better". The CMAM amplitudes are "better" for $80 \%$ of the choices, while for phases CMAM is "better" for 27\%, with CMAM and GSWM being "similar" for $62 \%$ of choices. We recall that the GSWM (Sect. 4) suffered from consistently low amplitudes. When comparisons of CMAM and GSWM2000 with the MFR are made the percentages are very similar but with a tendency for CMAM phases (magnitudes and slopes) to be "better" (65\% rather than 27\% in Table 1). Despite this, the phases in the two GSWMs are really quite similar overall; the new version is preferred because the global tidal structures (contours) are much better behaved (Fig. 5), especially in spring and summer. Although it was argued in Manson et al. (2001) that the "MK" GW parameterization was superior to the $H$ (Hines, 1997) parameterization, based upon global tidal structures in a figure similar in format to Fig. 10, the profiles from that latter experiment (not shown) are also closer to the MFR observations than is either GSWM model. This CMAM model has full chemistry, clouds and latent heat effects included, so that the tidal forcing should be more complete than in GSWM versions. Also it has the most realistic incorporation of GW effects possible at this time.

The diurnal tides are shown in Fig. 12 and it is immediately obvious that the agreement of CMAM with the MFR observations is less than for the semi-diurnal. In particular the summer CMAM amplitude values from $31^{\circ}$ to $52^{\circ} \mathrm{N}$ are much larger; the equinoctial CMAM amplitudes at Hawaii $\left(22^{\circ} \mathrm{N}\right)$ are much larger (factors of 2-4); and the phases, while often similar at $2^{\circ}-22^{\circ} \mathrm{N}$ or $70^{\circ} \mathrm{N}$, are also often significantly different (6h or more), e.g. Saskatoon and London in April. GSWM profiles were added again and are clearly closer to observations than is CMAM, e.g. summer amplitudes are closer to those observed at middle-high latitudes and phases more often overlap observations. In Table 1, although almost $30 \%$ of the 56 choices have "similar" GSWM and CMAM amplitude-phase values, $60-70 \%$ have the GSWM as "better". When comparisons with CMAM and GSWM2000 are made, the number of preferences for the latter decrease $(\sim 50 \%)$ and those for the CMAM increase $(\sim 25 \%)$. This is consistent with the assessments in Sect. 5 which favoured the original version of GSWM. It is not understood why the CMAM models the diurnal tide less well than the semi-diurnal tide, since diagnosis of the tidalprocesses within GCMs is very difficult and requires similar effort to that involved with operating and obtaining data from an individual radar! However, the diurnal tide of CMAM remains a rather useful description of the global tide.

\section{Final remarks and summary}

This section will be kept quite brief, as the individual comparisons with the respective GSWM versions (GSWM (1995) and GSWM2000) for the semi-diurnal and diurnal tides have been discussed rather completely within each section (Sects. 4 and 5) and, indeed, in Sect. 6 there was the opportunity to compare the CMAM and GSWM with the each other and the Radar data at a range of latitudes.

Briefly, in summary, we have compared the GSWM and GSWM2000 tides with the MF Radar tides in a useful va- 
riety of formats. For the semi-diurnal tide the new version demonstrated valuable improvements, especially with regard to global phase structures and the removal of the problematic short wavelengths from GSWM at high latitudes for the summer-months. Significant differences still remain however, with respect to amplitudes and vertical wavelengths, e.g. observed amplitude values are generally larger than modelled in summer, autumn and spring; the observed phase gradients and their variations with height differ in most months/seasons. Regarding the diurnal tide, the earlier study (Manson et al., 1999a) identified the GSWM in its 1995 form as being in excellent agreement with the MF Radars in the Pacific-North American quadrant. Unfortunately the GSWM2000 version is in less good agreement. Specific examples are the global phase structures, which show that the modelled lower latitude short wavelengths have spread even further into middle to high latitudes and, as such, are unobserved. Also the modelled equinoctial amplitudes, inevitably linked to the dominant tidal modes, are now much larger (factors of 2-3) than observed at middle latitudes and are beyond the expected speed biases (low by factors of up to 1.5) in the MF Radar winds. This is evidently linked to the extension of the short wavelength regime to higher latitudes. We have discussed the inherent limitations of the GSWM; e.g. absence of latent heat parameterizations above. Also, there is the fact that the 2-D model is being compared with observations at specific longitudes. We have discussed this issue and it is not thought to be a dominant factor in the comparisons we have made. However the recent paper by Oberheide et al. (2000) has made the essential point that when the GSWM uses assimilated data (CRISTA) for the winds and atmospheric conditions, agreement of the tides with observations (also from CRISTA) are improved.

The tides from the CMAM were of a disparate nature, since the semi-diurnal tides were in excellent agreement with observations while the diurnal tides were not. A statistical comparison with the semi-diurnal tides in the two GSWM versions showed a clear preference for the CMAM tides in both amplitudes and phases. This goodness of the CMAM semi-diurnal tide was also demonstrated in an earlier paper by Manson et al. (2001) which focussed on the CMAM model and the GW present in it. It is noted that the CMAM contains all of the physically expected sources for the tide, e.g. ozone and water vapour effects, as well as the modifying propagation conditions, e.g. winds and GW. With that in mind, the much poorer agreement of the CMAM diurnal tide with the MFR Radar tides comes as a surprise; here, either of the GSWM versions were statistically closer to observations with a preference for the GSWM. Careful diagnosis of the physical processes within CMAM would be needed to shed further light on this, and will be the subject of later studies.

Acknowledgements. The scientists gratefully acknowledge their national agencies: NSERC, Canada; NSF,USA; ARC, Australia. The first authors (Manson, Meek) also acknowledge support from the University of Saskatchewan and the Institute of Space and Atmospheric Studies.
Topical Editor D. Murtagh thanks N. Mitchell and S. Miyahara for their help in evaluating this paper.

\section{References}

Beagley, S. R., deGrandpre, J., Koshyk, J. M., McFarlane, N. A., and Shepherd, T. G.: Radiative dynamical climatology of the first generation Canadian middle atmosphere model, AtmosphereOcean, 293-331, 1997.

Burrage, M. D., Hagan, M. E., Skinner, W. R., Wu, D. L., and Hays, P. B.: Long-term variability in the solar diurnal tide observed by HRDI and simulated by the GSWM, Geophys. Res. Lett., 22, 2641-2644, 1995.

Burrage, M. D., Skinner, W. R., Gell, D. A., Hays, P. B., Marshall, A. R., Ortland, D. A., Manson, A. H., Franke, S. J., Fritts, D. C., Hoffman, P., McLandress, C., Niciejewski, R., Schmidlin, F. J., Shepherd, G. G., Singer, W., Tsuda, T., and Vincent, R. A.: Validation of mesosphere and lower thermosphere winds from the high resolution Doppler imager on UARS, J. Geophys. Res., 101, 10365-10392, 1996.

Forbes, J. M., Roble, R. G., and Fesen, C. G.: Acceleration, heating and compositional mixing of the thermosphere due to upwardpropagating tides, J. Geophys. Res., 98, 311-321, 1993.

Forbes, J. M., Hagan, M. E., Zhang, X., and Hackney, J.: Upper atmospheric tidal variability due to latent heat release in the tropical troposphere, Adv. Space Res., in press, 1999.

Groves, G. V.: Hough components of water vapour heating, J. Atmos. Terr. Phys., 44, 281-290, 1982.

Groves, G. V.: A global reference atmosphere from 18 to $80 \mathrm{~km}$, AFGL report TR-85-0129, 1985.

Groves, G. V., Final scientific report, AFOSR report 84-1145, 1987.

Hagan, M. E., Forbes, J. M., and Vial, F.: A numerical investigation of the propagation of the quasi 2-day wave into the lower thermosphere, J. Geophys. Res., 98, 23 193-23 205, 1993.

Hagan, M. E., Forbes, J. M., and Vial, F: On modeling migrating solar tides, Geophys. Res. Lett., 22, 893-896, 1995.

Hagan, M. E., Burrage, M. D., Forbes, J. M., Hackney, J., Randel, W. J., and Zhang, X.: GSWM-98: Results for migrating solar tides, J. Geophys. Res., 104, A4, 6813, 1999.

Hagan, M. E., Roble, R. G., and Hackney, J.: Migrating thermospheric tides, J.Geophys. Res., in press, 2001.

Hedlin, A. E.: Extension of the MSIS thermosphere model into the middle and lower atmosphere, J. Geophys. Res., 96, 1159-1172, 1991.

Hines, C. O.: Doppler spread parameterization of gravity wave momentum deposition in the middle atmosphere Part 2: Broad and quasi monochromatic spectra and implementation, J. of Atmos. Solar-Terr. Phys., 387-400, 1997.

Hocking, W. K., and Thayaparan, T.: Simultaneous and co-located observations of winds and tides by MF and meteor radars over London. Canada $\left(43^{\circ} \mathrm{N}, 81^{\circ} \mathrm{W}\right)$ during 1994-1996, Radio Science, 32, 833-865, 1997.

Isler, J. R., and Fritts, D. C.: Gravity wave variability and interaction with lower-frequency motions in the mesosphere and lower thermosphere over Hawaii, J. Atmos. Sci., 53, 37-48, 1996.

Jacobi, Ch., Portnyagin, Y. I., Solovjova, T. V., Hoffman, P., Singer, W., Fahrutdinova, A. N., Ishmuratov, R. A., Beard, A. G., Mitchell, N. J., Muller, H. G., Schminder, R., Kurschner, D., Manson, A. H., and Meek, C. E.: Climatology of the semidiurnal tide at $52-56^{\circ} \mathrm{N}$ from ground-based radar wind measurements 1985-1995, J. Atmos. Solar-Terr. Phys., 61, 975-991, 1999. 
Keating, G. M., Pitts. M. C., and Chen, C.: Improved reference models for middle atmosphere ozone, Adv. Space Res., 10, 637649, 1990.

Manson, A. K. and Meek, C. E.: Dynamics of the middle atmosphere at Saskatoon $\left(52^{\circ} \mathrm{N}, 107^{\circ} \mathrm{W}\right)$ : a spectral study during 1981, 1982, J. Atmos. Terr. Phys., 48, 1039-1055, 1986.

Manson, A. H., Meek, C. E., Brekke, A., and Moen, J.: Mesosphere and lower thermosphere $(80-120 \mathrm{~km})$ winds and tides from near Troms $\varnothing\left(70^{\circ} \mathrm{N}, 19^{\circ} \mathrm{E}\right)$ : comparisons between radars (MF, EISCAT, VHF) and rockets, J. Atmos. Terr. Phys., 54, 927-950, 1992.

Manson, A. H., Yi, F., Hall, G., and Meek, C. E.: Comparisons between instantaneous wind measurements made at Saskatoon $\left(52^{\circ} \mathrm{N}, 107^{\circ} \mathrm{W}\right)$ using the co-located medium frequency radars and Fabry-Perot interferometer instruments: climatologies (1988-1992) and case studies, J. Geophys. Res., 101, $29553-$ 29563, 1996.

Manson, A. H., Meek, C. E., and Hall, G. E.: Correlations of gravity waves and tides in the mesosphere over Saskatoon, J. Atmos. Solar-Terr. Phys., 60, 1089-1107, 1998.

Manson, A. H., Meek, C. E., Hagan, M., Hall, C., Hocking, W., MacDougall, J., Franke, S., Riggin, D., Fritts, D., Vincent, R., and Burrage, M.: Seasonal variations of the semi-diurnal and diurnal tides in the MLT: multi-year MF radar observations from 2 to $70^{\circ} \mathrm{N}$, and the GSWM tidal model, J. Atmos. Solar-Terr. Phys., 61, 809-828, 1999a.

Manson, A. H., Meek, C. E., Hall, C., Hocking, W., MacDougall, J., Franke, S., Igarashi, K., Riggin, D., Fritts, D., and Vincent, B.: Gravity wave spectra, directions and wave interactions: Global MLT-MFR network, Earth Planets Space, 51, 543-562, $1999 \mathrm{~b}$.

Manson, A. H., Meek, C. E., Hall, C., Hocking, W., MacDougall, J., Franke, S., Riggin, D., Fritts, D., Vincent, B., and Hagan, M.: Seasonal Variations of the Semi-Diurnal and Diurnal Tides in the MLT: Multi-Year MF Radar Observations from $2-70^{\circ} \mathrm{N}$ and the GSWM, Report \#1, Atmospheric Dynamics Group, Institute of Space and Atmospheric Studies, U. of S. Saskatoon, Canada, $1999 \mathrm{c}$

Manson, A. H., Meek, C. E., Koshyk, J., Franke, S., Fritts, D., Riggin, D., Hall, C., Hocking, W., MacDougall, J., Igarashi, K., and Vincent, B.: Gravity Wave Activity and Dynamical effects in the Middle Atmosphere $(60-90 \mathrm{~km})$ : Observations from an MF/MLT Radar Network, and results from the Canadian Middle Atmosphere Model (CMAM), J. Atmos. Solar-Terr. Phys., submitted, 2001.

McFarlane, N. A.: The effect of orographically excited gravity wave drag on the general circulation of the lower stratosphere and troposphere, J. of Atmos. Sc., 1775-1800, 1987.

Medvedev, A. S. and Klaassen, G. P.: Vertical evolution of gravity wave spectra and the parameterization of associated wave drag, J. Geophys. Res., 25 841-25 853, 1995.

Medvedev, A. S. and Klaassen, G. P.: Parameterization of gravity wave momentum deposition based on nonlinear wave interactions: basic formulation and sensitivity tests, J. Atmos. SolarTerr. Phys., 62, 11, 1015, 2000.

Meek, C. E.: An efficient method for analysing ionospheric drifts data, J. Atmos. Terr. Phys., 41, 251-258, 1980.

Meek, C. E., Manson, A. H., Burrage, M. D., Garbe, G., and Cogger, L. L.: Comparisons between Canadian prairie MF radars, FPI (green and OH lines) and UARS HRDI systems, Ann. Geophysicae, 15, 1099-1110, 1997.

Miyahara, S., Yoshida, Y., and Miyoshi, Y.: Dynamic coupling between the lower and upper atmosphere by tides and gravity waves, J. Atmos. Terr. Phys., 55, 1039-1053, 1993.

Oberheide, J., Hagan, M. E., Ward, W. E., Riese, R., and Offermann, D.: Modeling the diurnal tide for the Cryogenic Infrared Spectrometers and Telescopes (CRISTA) 1 time period, J. Geophys. Res., 105, 24 917-24 929, 2000.

Pancheva, D. N., Mitchell, N. J., and Hagan, M. E., et al.: Global scale tidal structure during the PSMOS campaign of June-August 1999 and comparisons with the Global Scale Wave Model, J. Atmos. Solar Terr. Phys., in press, 2001.

Portnyagin, Yu. I. and Solov'era, T. V.: An empirical model of the meridional wind in the mesopause-lower thermosphere - part 1: a mean monthly empirical model, Russian J. Met. And Hydr., 10, 28-35, 1992a.

Portnyagin, Yu. I. and Solov'era T. V.: An empirical model of the meridional wind in the mesopause-lower thermosphere - part 2: height-latitude features of basic components of meridional wind seasonal variations, Russian J. Met. And Hydr., 11, 28-35, $1992 b$.

Shepherd, G. G., Roble, R. G., Zhang, S. P., McLandress, C., and Wiens, R. H.: Tidal influence on midlatitude airglow: Comparison of satellite and ground-based observations with TIME-GCM predictions, J. Geophys. Res., 103, A7, 14 741-14 751, 1998.

Thayaparan, T., Hocking, W. K., and MacDougll, J.: Middle atmospheric winds and tides over London, Canada $\left(43^{\circ} \mathrm{N}, 81^{\circ} \mathrm{W}\right)$ during 1992-1993, Radio Sci., 30, 1293-1309, 1995.

Ward, W. E.: Tidal mechanisms of dynamical influence on oxygen re-combination airglow in the mesosphere and lower thermosphere, Adv. Space Res., 21, 6, 795-805, 1998. 